Monetary and macroprudential policy with foreign

currency loans

Michał Brzoza-Brzezina, Marcin Kolasa, Krzysztof Makarski 


\section{Monetary and macroprudential policy with foreign currency loans}

\author{
Michał Brzoza-Brzezina \\ WSE \\ National Bank of Poland
}

\author{
Marcin Kolasa \\ WSE \\ National Bank of Poland
}

\author{
Krzysztof Makarski \\ FAME|GRAPE \\ WSE
}

National Bank of Poland

\section{Abstract}

In a number of countries a substantial proportion of mortgage loans is denominated in foreign currency. In this paper we demonstrate how their presence affects economic policy and agents' welfare. To this end we construct a small open economy model with financial frictions, where housing loans can be denominated in domestic or foreign currency. The model is calibrated for Poland - a typical small open economy with a large share of foreign currency loans (FCL). We show that the presence of FCLs negatively affects the transmission of monetary policy and deteriorates the output-inflation volatility trade-off it faces. The trade-off can be improved with macroprudential policy but the outcomes are still worse than under this same policy mix applied to an economy with domestic currency debt. We also demonstrate that a high share of FCLs is harmful for social welfare, even if financial stability considerations are not taken into account. Finally, we show that regulatory policies that discriminate against FCLs may have a negative impact on economic activity and discuss the redistributive consequences of forced currency conversion of household debt.

Keywords:

foreign currency loans, monetary policy, macroprudential policy, DSGE

\section{JEL Classification}

E32, E44, E58

Corresponding author

Krzysztof Makarski, k.makarski@grape.org.pl

\section{Acknowledgements}

The project was conducted in the context of the ESCB's Macro-prudential Research Network (MaRs). The views expressed herein are those of the authors and not necessarily those of Narodowy Bank Polski. We would like to thank Lukasz Drozd and Istvan Konya for helpful discussions and two anonymous referees for useful suggestions. Comments received at the 2nd NBP Summer Workshop, Annual Meeting of the Society for Economic Dynamics in Toronto, 20th Computing in Economics and Finance conference, 30th Annual Congress of the EEA in Mannheim, workshop at the University of Surrey and seminar at Magyar Nemzeti Bank are also gratefully acknowledged.

Published by:

ISSN:
FAME | GRAPE

2544-2473

(c) with the authors, 2017 


\section{Introduction}

Foreign currency loans (FCL) have become highly popular in many emerging and some advanced economies since the early 2000s. In the European Union their presence is particularly sizable in Bulgaria, Hungary, Romania, Poland, and even Austria. In 2013 FCLs accounted for approximately $60 \%$ of loans to the non-banking sector in the former three countries, in Poland this share was close to 30\%, and in Austria slightly below 20\% (SNB, 2013). If one considers only mortgages, the share of FCLs was even higher. For instance, in Poland, over 50\% of mortgage loans outstanding in 2013 were denominated in foreign currency.

Foreign currency loans offer some advantages to borrowers, in particular lower interest rates and possibly longer maturities. At the same time, however, they constitute an important source of systemic risk in the economy. Sharp depreciations of the exchange rate bring about a surge in servicing costs expressed in borrowers' income currency, which may, in most extreme cases, lead to mass defaults and systemic banking crises (Yesin, 2013). FCLs have also been recognized to affect the transmission of monetary policy. In particular, the impact of domestic interest rates on the economy may be weaker when borrowers are able to substitute domestic currency loans (DCL) for FCLs. The impact of foreign currency lending on the economy has repeatedly gained attention of policymakers including microprudential (regulatory), macroprudential and monetary authorities (Dübel and Walley, 2010; ESRB, 2011; Lim et al., 2011; Dell'Ariccia et al., 2016). In many countries lending in foreign currency to households has been restricted by the financial supervision over the last few years.

This paper analyzes the role of FCLs to households through the lens of a dynamic stochastic general equilibrium (DSGE) model. As such it connects two important streams in the literature: the modeling literature on financial frictions and the empirical literature on the relationship between FCLs and macroeconomic policy.

From the modeling perspective we build on the seminal papers of Kiyotaki and Moore (1997) and Iacoviello (2005), who developed a workhorse DSGE model with credit constraints and housing that serves as collateral. Models based on this framework have been successfully applied in the past to analyze a number of issues, like the impact of macroprudential policy on the business cycle or spillovers from the housing market to the economy (e.g. Gerali et al., 2010; Iacoviello and Neri, 2010). This framework fits also our needs since it contains the key ingredients given our research questions, i.e. mortgage loans and the possibility to introduce regulatory policy in the form of LTV requirements. We modify this setup in several directions. In particular, we extend it to a small open economy setting and introduce FCLs.

Regarding the main topic at hand, our study relates to the literature on foreign currency lending and its connections with monetary and macroprudential policies. This literature has a strong empirical flavor. As regards the links to monetary policy, the relationship between 
interest rates, exchange rates and FCLs is crucial. As documented in Magud et al. (2014), both fixed exchange rate regimes or high interest rate differentials increase the share of foreign currency loans. The latter finding has been confirmed in several other studies including Egert et al. (2007), Rosenberg and Tirpák (2009) and Brzoza-Brzezina et al. (2010), and is crucial to understand how FCLs can weaken the monetary transmission. Especially the last paper deals explicitly with this problem. Based on a panel of four Central European countries, the study shows that after a monetary policy tightening, more than $50 \%$ of eliminated DCLs can return to the economy as FCLs.

Much less research has been conducted on the link between macroprudential policy and FCLs. The main question of interest so far has been whether appropriately designed regulation is able to reduce the share of FCLs in the economy. For instance, Lim et al. (2011) show that some regulatory actions targeted at limiting the amount of FCLs have been efficient in the past. However, to our knowledge, the impact of FCLs on the effectiveness of macroprudential policy has not been analyzed so far.

This paper's contribution to the literature is twofold. First, we provide a formal framework for modeling FCLs for households in a macroeconomic environment. ${ }^{1}$ To this end, we construct a microfounded small open economy model where agents can borrow both in domestic and foreign currency. Second, we use this model to answer several important questions either not tackled by the literature, or touched upon only in econometric frameworks. These are: (i) How does the presence of foreign currency denominated mortgages affect monetary and macroprudential policy transmission, and how does it impact the output-inflation volatility trade-off? (ii) What are the implications of foreign currency lending for household welfare? (iii) What are the macroeconomic effects of using regulation to discriminate against FCLs? (iv) What are the consequences of currency depreciation and a subsequent conversion of FCLs to DCLs imposed by the government?

To answer these questions we construct a model that contains the most important ingredients needed. This means that we abstract from several features that, while allowing for a deeper investigation of the FCL problem, do not seem crucial given our questions. In particular, the steady-state share of FCLs is exogenous in our model. We motivate this choice by the observation that the presence of this type of loans is mainly determined by institutional arrangements and sources of aggregate risk (see Kolasa, 2016), which can be treated as given. It also allows us to easily compare the economies that differ only in the share of FCLs. Moreover, we abstract away from possible household and bank defaults that may follow massive exchange rate depreciations as we want to focus on a standard business cycle environment. In other words, this paper does not deal with systemic risk or other financial stability issues. It is also worth noting in this context that, at least in Europe,

\footnotetext{
${ }^{1} \mathrm{~A}$ number of papers have analyzed foreign currency lending in the corporate sector, see e.g. Elekdag and Tchakarov (2007), Gertler et al. (2007) or Kolasa and Lombardo (2014).
} 
defaults on mortgage debt are rare in normal times. ${ }^{2}$

Our main findings are as follows. First, FCLs negatively affect the transmission of monetary policy but do not significantly impact on the effectiveness of macroprudential policy. The presence of foreign currency denominated household debt also deteriorates the inflationoutput volatility trade-off, even if monetary policy is complemented with macroprudential policy in a coordinated manner. Second, we find that FCLs increase welfare when domestic interest rate shocks are strong and decrease it when international risk premium (exchange rate) shocks dominate. In a rich stochastic environment, a large presence of FCLs is found to be welfare reducing. Third, eliminating the described inefficiencies through regulation discriminating against FCLs may have a short-term contractionary impact on the economy. Fourth, we simulate a scenario under which the government responds to currency depreciation by enforcing a conversion of FCLs to DCLs at the original exchange rate. We show that such scenario benefits the borrowers but hurts bank owners.

The rest of the paper is structured as follows. Section two describes the model and section three its calibration. Section four discusses the impact of foreign currency loans on the transmission of monetary and macroprudential policy and on welfare. Section five concludes.

\section{Model}

Our departure point is a standard New Keynesian framework for a small open economy, which we extend to incorporate credit in a way that allows us to accommodate both domestic and foreign currency denomination of loans. In what follows we describe in detail our extension, which concerns mainly the household sector, and provide only a brief summary of the model's remaining building blocks. A full list of equations describing the equilibrium in our model can be found in the Appendix.

\section{$2.1 \quad$ Households}

To introduce credit, we distinguish between two types of households whose preferences differ in the degree to which they discount the future utility flows. In this way we obtain a distinction between natural borrowers (impatient households) and lenders (patient households), denoted by $I$ and $P$, respectively. The measure of borrowers is $\omega_{I}$ while that of lenders equals $\omega_{P}=1-\omega_{I}$. Within each group, a representative agent $\iota$ maximizes

$$
\mathbb{E}_{0}\left\{\sum_{t=0}^{\infty} \beta_{i}^{t}\left[\log \left(c_{i, t}(\iota)-\xi c_{i, t-1}\right)+A_{\chi} \log \chi_{i, t}(\iota)-A_{n} \frac{n_{i, t}(\iota)^{1+\sigma_{n}}}{1+\sigma_{n}}\right]\right\}
$$

\footnotetext{
${ }^{2}$ There are very few papers that allow for household and bank bankruptcies in a quantitative business cycle framework. Notable exceptions include Elenev et al. (2016) and Mendicino et al. (2016), but none of them looks at the role of FCLs.
} 
where $i \in\{I, P\}$ and $\beta_{I}<\beta_{P}$. In the formula above, $c_{t}$ is consumption, $\chi_{t}$ denotes housing stock and $n_{t}$ is labor supply.

Patient households' maximization is subject to a standard budget constraint

$$
\begin{aligned}
P_{t} c_{P, t}(\iota)+P_{\chi, t}\left(\chi_{P, t}(\iota)\right. & \left.-\left(1-\delta_{\chi}\right) \chi_{P, t-1}(\iota)\right)+P_{k, t}\left(k_{t}(\iota)-\left(1-\delta_{k}\right) k_{t-1}(\iota)\right)+D_{t}(\iota) \leq \\
\leq & W_{P, t} n_{P, t}(\iota)+R_{k, t} k_{t-1}(\iota)+R_{t-1} D_{t-1}(\iota)+\Pi_{t}+T_{P, t}+\Xi_{P, t}(\iota)
\end{aligned}
$$

where $k_{t}$ is physical capital, $R_{k, t}$ denotes its rental rate, $\Pi_{t}$ is profits from monopolistically competitive firms and banks, $T_{i, t}$ is lump-sum net transfers, $\Xi_{i, t}$ stands for net payments from insurance policies traded between households of a given type and insulating them from idiosyncratic labor income risk, $P_{\chi, t}$ and $P_{k, t}$ denote house and physical capital prices, $W_{i, t}$ is nominal wage while $D_{t}$ stands for deposits denominated in domestic currency and paying risk-free rate $R_{t}$, fully controlled by the monetary authority.

Impatient households do not accumulate physical capital, do not hold any equity, and can take loans both in domestic and foreign currency. Their budget constraint can be written as

$$
\begin{array}{r}
P_{t} c_{I, t}(\iota)+P_{\chi, t}\left(\chi_{I, t}(\iota)-\left(1-\delta_{\chi}\right) \chi_{I, t-1}(\iota)\right)+R_{H, t-1} L_{H, t-1}(\iota)+S_{t}(1+\tau) R_{F, t-1} L_{F, t-1}(\iota) \leq \\
\leq W_{I, t} n_{I, t}(\iota)+L_{t}(\iota)+T_{I, t}+\Xi_{I, t}(\iota) \quad(3)
\end{array}
$$

where $R_{H, t}$ and $R_{F, t}$ denote interest paid on these loans, $\tau$ is a tax set by the macroprudential authority (to be explained in Section 4.4), $S_{t}$ is the nominal exchange rate, and the loan aggregate is defined using the following constant elasticity of substitution (CES) function ${ }^{3}$

$$
L_{t}(\iota)=\left[\eta_{L, t}^{\frac{1}{\phi_{L}}} L_{H, t}(\iota)^{\frac{\phi_{L}-1}{\phi_{L}}}+\left(1-\eta_{L, t}\right)^{\frac{1}{\phi_{L}}}\left(S_{t} L_{F, t}(\iota)\right)^{\frac{\phi_{L}-1}{\phi_{L}}}\right]^{\frac{\phi_{L}}{\phi_{L}-1}}
$$

where $\eta_{L, t}$ denotes the share of domestic currency loans in total loans that is governed by a stochastic process.

The formula above implies that we treat domestic and foreign currency loans as imperfect substitutes even in a non-stochastic environment. This modeling choice can be interpreted as a short-cut for households' preferences or implicit costs of changing the loan portfolio structure. It also helps avoid excessive sensitivity of the portfolio decisions to shocks (at least when solved with perturbation techniques), thus serving a similar purpose as transaction costs in Tille and van Wincoop (2010) or Devereux and Yetman (2010).

Additionally, impatient households' optimization is subject to the following collateral

\footnotetext{
${ }^{3} \mathrm{~A}$ similar functional form is used by Poutineau and Vermandel (2015) to aggregate loans from foreign and domestic banks. Additionally, to offset implicit transfers from impatient to patient households that arise from the loan aggregate $L_{t}$ falling short of the financial flows generated by the banking sector $L_{H, t}+S_{t} L_{F, t}$, this difference is rebated back to impatient households in a lump sum manner and included in $\Xi_{t}$.
} 
constraint

$$
R_{H, t} L_{H, t}(\iota)+\mathbb{E}_{t}\left\{(1+\tau) R_{F, t} S_{t+1} L_{F, t}(\iota)\right\} \leq m_{t}\left(1-\delta_{\chi}\right) \mathbb{E}_{t}\left\{P_{\chi, t+1} \chi_{I, t}(\iota)\right\}
$$

where $m_{t}$ denotes the loan to value (LTV) ratio on total loans. We assume that it is fully controlled by the macroprudential authority.

The first order conditions describing the optimal choice of loans taken by borrowing households imply

$$
\begin{aligned}
u_{I, t}=\left\{\eta _ { L } \left(\Theta_{t} R_{H, t}+\right.\right. & \left.\beta_{I} R_{H, t} \mathbb{E}_{t}\left[\frac{u_{I, t+1}}{\pi_{t+1}}\right]\right)^{1-\phi_{L}} \\
& \left.+\left(1-\eta_{L}\right)\left(\Theta_{t} R_{F, t} \mathbb{E}_{t}\left[\frac{S_{t+1}}{S_{t}}\right]+\beta_{I} \mathbb{E}_{t}\left[\frac{u_{I, t+1}}{\pi_{t+1}} R_{F, t} \frac{S_{t+1}}{S_{t}}\right]\right)^{1-\phi_{L}}\right\}^{\frac{1}{1-\phi_{L}}}
\end{aligned}
$$

where $u_{I, t}$ and $\Theta_{t}$ denote, respectively, marginal utility of consumption and the Lagrange multiplier on the collateral constraint (5). Basically, this equation says that the marginal benefit of an additional unit of borrowing must be equal to the marginal cost related to tightening of the LTV constraint and expected repayment in the future. This cost includes terms related to both DCLs and FCLs, with weights governed by their steady state shares in the loan portfolio. It is easy to see that if we set $\eta_{t}=1$ so that the share of FCLs is zero, formula 6 reduces to the standard Euler equation describing equilibrium borrowing by financially constrained agents.

\subsection{Banking Sector}

Banks take deposits form patient households and use them to finance differentiated loans in domestic or foreign currency, which they sell in monopolistically competitive markets. These differentiated loans are purchased by loan aggregators, who combine them into homogeneous domestic and foreign currency loans, which are offered to impatient households in perfectly competitive markets.

\subsubsection{Loan Aggregators}

There are domestic and foreign loan aggregators of type $h \in\{H, F\}$, operating in a perfectly competitive environment. They take loans from banks indexed by $j \in[0,1]$, aggregate them and extend to households. Each loan aggregator maximizes profits

$$
R_{h, t} L_{h, t}-\int_{0}^{1} R_{h, t}(j) L_{h, t}(j) d j
$$


subject to the following Dixit-Stiglitz aggregator

$$
L_{h, t}=\left[\int_{0}^{1} L_{h, t}^{\frac{1}{\mu_{L}}}(, j) d j\right]^{\mu_{L}}
$$

where $\mu_{L}$ measures markups in financial intermediation that give rise to spreads between the loan and deposit rates. The solution to the problem defined above results in the following demand for loans from bank $j$

$$
L_{h, t}(j)=\left(\frac{R_{h, t}(j)}{R_{h, t}}\right)^{\frac{\mu_{L}}{1-\mu_{L}}} L_{h, t}
$$

\subsubsection{Banks}

There is a continuum of banks indexed by $j$. They supply domestic and foreign currency loans, and operate in a monopolistically competitive environment. Banks refinance these loans by collecting deposits from patient households and by borrowing from abroad. Each bank chooses the quantity and price of her loans to maximize

$$
\mathbb{E}_{0}\left\{\beta_{P} \frac{u_{P, t+1}}{P_{t+1}}\left[R_{H, t}(j) L_{H, t}(j)+S_{t+1} R_{F, t}(j) L_{F, t}(j)-R_{t} D_{t}(j)-S_{t+1} \rho_{t} R_{t}^{*} D_{t}^{*}(j)\right]\right\}
$$

subject to the demand schedules (9) and the flow of funds constraint

$$
L_{H, t}(j)+S_{t} L_{F, t}(j)=D_{t}(j)+S_{t} D_{t}^{*}(j)
$$

where $u_{P, t}$ is patient agents' marginal utility of real income, $D_{t}^{*}$ is borrowing from abroad, $R_{t}^{*}$ is the interest rate set by the foreign monetary authority and $\rho_{t}$ is the risks premium that depends on net foreign debt and risk premium shocks. ${ }^{4}$ It is important to note that since in our model only banks can borrow from abroad, aggregate foreign borrowing $D_{t}^{*} \equiv \int_{0}^{1} D_{t}(j) d j$ is also the economy's net foreign debt, equal to cumulative current account deficits. Note that the flow of funds constraint 11 does not uniquely link foreign currency loans $L_{F, t}$ to borrowing from abroad $D_{t}^{*}$, i.e. banks can also refinance the former using domestic currency deposits taken from domestic patient households.

The bank problem gives rise to the standard UIP condition

$$
\mathbb{E}_{t}\left[\frac{u_{P, t+1}}{\pi_{t+1}}\right] R_{t}=\mathbb{E}_{t}\left[\frac{u_{P, t+1}}{\pi_{t+1}} \frac{S_{t+1}}{S_{t}}\right] \varrho_{t} R_{t}^{*}
$$

\footnotetext{
${ }^{4}$ The dependence of the risk premium on foreign debt is introduced only to render the model stationary and calibrated such that it does not substantially affect the model dynamics. The goal of including risk premium shocks is to increase exchange rate volatility implied by the model. This type of shocks are now standard in the applied DSGE literature, see e.g. Justiniano and Preston (2010).
} 
and optimal lending rates charged on impatient households

$$
\begin{aligned}
R_{H, t}(j) & =\mu_{L} R_{t} \\
R_{F, t}(j) & =\mu_{L} \rho_{t} R_{t}^{*}
\end{aligned}
$$

\subsection{Other building blocks}

Since the rest of the model is fairly standard, we only briefly summarize its main components, referring the reader to the Appendix for details. Output is produced by monopolistically competitive firms that combine labor and capital services using a standard Cobb-Douglas technology. Their prices are set in a staggered fashion according to the Calvo scheme and are sticky in the consumers' currency (local currency pricing). Labor supplied by patient and impatient households is aggregated into labor services using a CES technology. Capital and housing are purchased by households from perfectly competitive capital and housing goods producers, who combine the existing stocks with capital and housing-specific invest-

ment, subject to adjustment costs and asset-specific shocks. Final consumption and capital investment goods are defined as CES aggregators of domestic and foreign goods, while residential investment and government purchases are assumed to have only domestic content. As typically done in a small open economy setup, the foreign block is exogenous.

The model is closed by imposing a standard set of market clearing conditions and defining the rules for the fiscal, monetary and regulatory authorities. More specifically, government spending is modeled as an exogenous process and the lump-sum taxes levied on households are adjusted such that the government budget is balanced each period. The central bank adjusts its short-term interest rates according to a Taylor-like rule that allows for interest rate smoothing and includes i.i.d. monetary shocks. Finally, the LTV ratio set by the regulatory authority is assumed to be exogenous (unless stated otherwise).

The model economy is driven by nine stochastic shocks affecting firm productivity, risk premium, composition of the loan basket, government spending, the interest rate rule, the LTV ratio, as well as the following three foreign variables: output, inflation and the interest rate. All of these shocks follow first-order autoregressions, except for monetary policy shocks, which are assumed to be white noise. We also allow for correlation between innovations to the three foreign shocks.

\section{Calibration}

We calibrate the model to Polish data. Several parameters are set to match the key steady state ratios, reported in Table 1, using the 2000-2012 averages as the targets. Other parameters are taken from the literature. The calibrated values of structural parameters and 
stochastic shocks are summarized in Tables 2 and 3. Throughout, the unit of time is one quarter.

We choose 0.0054 as the housing stock depreciation rate and 0.56 as the housing weight in utility to match, respectively, the residential investment share in output equal to $2.8 \%$ and the steady state housing stock to annual output ratio of 1.3. The share of impatient households is calibrated at 0.75 to fit the mortgage loans to annual output ratio of $75 \%$. Following Coenen et al. (2008), we choose transfers from patient to impatient agents so that consumption of the latter falls short of that of the former by no more than $25 \%$. Finally, we calibrate markups in the banking sector to match the average spread between the lending rate and the policy rate of $190 \mathrm{bp}$ annually. Setting the weight of labor in utility to 110 allows us to match the share of working time of $32 \%$. Finally, the share of FCLs in the loan aggregator (4) is calibrated at 0.5 , roughly in line with the post-crisis data on lending to Polish households.

While calibrating households' preferences, we follow the literature. Similarly to Iacoviello and Neri (2010), we set the discount factors for patient and impatient households to 0.993 and 0.985 , respectively. This difference also guarantees that, for the magnitude of shocks considered in this paper, the collateral constraint (5) is always binding. The inverse of the Frisch elasticity as well as the inverse of the intertemporal elasticity of substitution in consumption are both set to 2. Following Brzoza-Brzezina et al. (2014), we calibrate the degree of habit formation in consumption to 0.75. Consistently with Polish data, we pick 0.85 as the steady-state LTV ratio.

The steady state markups in the labor and product markets are set to $20 \%$. The capital share in output is calibrated at the standard value of 0.32. Following Coenen et al. (2008), we set the elasticity of substitution between domestic and imported goods to 1.5, and the elasticity of substitution between patient and impatient households' labor to $6 .{ }^{5}$

We calibrate the degree of price stickiness in line with Brzoza-Brzezina et al. (2014), which additionally is supported by empirical evidence on price stickiness in Poland and the euro area presented in Macias and Makarski (2013) and Dhyne et al. (2006). The Calvo probabilities for domestic, import and export prices are all set to 0.75 . The sensitivity of the risk premium is fixed at 0.02 , which ensures that foreign debt is stabilized at zero in the long run without substantially affecting the model's short-run dynamics.

We parametrize the Taylor rule in line with estimated DSGE models for Poland, i.e. interest rate smoothing equal to 0.75 , the long-run response to inflation of 2 and that to output equal to 0.5 . The steady state inflation rate is set to $0.5 \%$ quarterly, which is close to the inflation target in Poland.

One of the structural parameters that cannot be taken directly from the literature is the elasticity of substitution between foreign and domestic currency loans. We calibrate

\footnotetext{
${ }^{5}$ To be precise, Coenen et al. (2008) distinguish between Ricardian and rule-of-thumb agents.
} 
it somewhat arbitrarily at 6 . It has to be borne in mind, however, that the value of this parameter, while important for the portfolio dynamics, does not affect the first-order accurate behavior of other model variables nor their second-order accurate unconditional moments. Whenever it does impact on our results, like in the case of deterministic simulations, we discuss their sensitivity to alternative values.

The parameters describing stochastic shocks are calibrated to match the model moments to key macroeconomic time series, all of which are detrended with the Hodrick-Prescott filter. More specifically, since foreign output, inflation and interest rates are exogenous to the rest of the model, we estimate their first-order autoregressive processes outside of the model using euro area data. We proceed similarly with government expenditures by fitting an $\mathrm{AR}(1)$ process to the Polish government consumption time series. Since macroprudential policy was not used in Poland during the analyzed time period, while calibrating the model we keep the LTV ratio $m_{t}$ constant and set the tax on FCLs $\tau$ to zero.

The remaining stochastic shocks as well as the elasticity of the residential and nonresidential investment adjustment cost are calibrated so that the weighted distance between the selected moments from the data and their model-based counterparts is minimized. The procedure is similar to the simulated method of moments used e.g. in Ruge-Murcia (2012). The only difference is that in our case we do not run simulations but rather use ergodic moments implied by the model solution.

More precisely, consider stationary data $x_{t}$. Denote the vector of moments computed from this data as $m\left(x_{t}\right)$. For any parameter $\theta \in \Theta$ (for which the solution to the model exists), we can compute the moments from the model $m(x(\theta))$. The parameter estimates $\hat{\theta}$ are chosen as follows

$$
\hat{\theta}=\underset{\theta \in \Theta}{\arg \min }\left[m\left(x_{T}\right)-m(x(\theta))\right]^{\prime} \mathbf{W}\left[m\left(x_{T}\right)-m(x(\theta))\right]
$$

where $\mathbf{W}$ is a diagonal matrix of the long-run variance of the moments computed using the Newey-West estimator with a Barlett kernel and bandwidth given by the integer of $4(T / 100)^{2 / 9}$, and $T$ denotes the sample size. As regards the moments collected in $m$, we use the standard deviations and first order autocorrelations of the following nine domestic variables: output, consumption, non-residential investment, residential investment, inflation, the short-term interest rate, domestic currency mortgage loans, foreign currency mortgage loans and the real exchange rate.

To show the workings of our model, in Table 4 we present the moments from the model against the ones calculated using the data. We obtain an adequate data fit, except for the mismatch of correlation of inflation with output and underestimation of real exchange rate volatility. However, given that the former is known to vary over time and the fact that the scale of exchange rate fluctuations is usually underestimated in this class of models, we 
consider our model fit to the data satisfactory.

\section{Results}

Our model can serve a variety of purposes and we are now ready to present the findings. We begin with discussing the implications of FCLs for business cycle dynamics. Then we analyze the impact of FCLs on the transmission and effectiveness of monetary and macroprudential policies. Next we check how the presence of FCLs affects agents' welfare. We finish with two policy experiments. First, we simulate a regulatory scenario that changes the share of FCLs in total loans and discuss its macroeconomic implications. Finally, we simulate a scenario of currency conversion.

\subsection{Business cycle implications of foreign currency loans}

Before we present the consequences of FCLs on monetary and macroprudential policies and on welfare, we first discuss their implications for the business cycle. Table 5 presents, for various steady-state shares of FCLs, the model-implied standard deviations and correlations with output of key macrovariables.

The following observations can be made. First of all, if mortgage loans are taken in foreign currency, the economy becomes less stable. While the effect on output can be considered moderate as its standard deviation increases by just $5 \%$ if we move from zero to $100 \%$ share of FCLs, it is much stronger for those variables that can be considered important from the welfare perspective. In particular, the volatility of consumption more than doubles and that of housing investment increases significantly. A higher proportion of FCLs also implies a more volatile credit. In contrast, inflation is hardly affected. The main reason for this increase in macroeconomic volatility is that, with a large share of FCLs, impatient households' balance sheets become very sensitive to fluctuations in the exchange rate, which significantly affects their consumption and housing demand. Moreover, since the central bank responds to fluctuations in output, an increase in their amplitude implies stronger adjustments of the

short-term interest rate, which makes the exchange rate and hence borrowers' expenditures even more volatile. It is worth noting that the effect of FCLs on aggregate volatility is non-linear: an increase in their share from zero to $50 \%$ has a significantly lower impact than a move from $50 \%$ to $100 \%$. Interestingly, the former shift has barely any effect on output volatility.

Overall, this discussion already suggests that lending in foreign currency to households might not be good for aggregate welfare, and for that of impatient households in particular. We look at this issue more formally in subsection 4.3 . 


\subsection{Foreign currency loans and effectiveness of monetary and macro- prudential policies}

We now check how foreign currency loans affect the transmission of monetary policy. The relevant impulse response functions are presented in Figure 1. In all of these simulations the initial total borrowing is the same so that the differences in the plotted reactions are only due to differences in the steady state composition of the loan portfolio held by impatient households. As a benchmark we show the responses to a monetary policy shock in the absence of FCLs. In this case we have the standard financial accelerator at work, which, as known from the literature, amplifies monetary transmission. Lower lending after the monetary policy shock drives down housing demand, lowers house prices and leads to a tightening of the collateral constraint. As a result, consumption further declines and so do output and inflation. If all loans are denominated in foreign currency, the financial accelerator is much weaker. This is because the relevant (i.e. foreign) interest rate does not change while the exchange rate appreciates, boosting impatient households' financial position. Finally, the impulse responses for our calibrated case (with $50 \%$ of FCLs) are located between these two extremes.

Our second experiment shows how the denomination of loans affects the potency of macroprudential policy, measured as the economy's response to changes in the LTV ratio. This is shown in Figure 2, which illustrates the effects of a negative 1\% LTV shock, with an autoregressive coefficient set to 0.95 . This time the difference between the impulse responses for various levels of foreign currency lending is small. To see why, note that an LTV shock affects the real economy but has little effect on inflation, while the monetary authority responds mainly to the latter. As a result, the domestic interest rate moves only slightly (not reported) and hence the exchange rate movements are moderate. Actually, the fall in output caused by an LTV tightening implies some monetary policy easing and exchange rate depreciation, which hits impatient households' balance sheets if loans are denominated in foreign currency. Hence, the presence of FCLs even slightly amplifies the effects of macroprudential policy, but this effect is small.

Both implications of FCLs for the business cycle and for the effectiveness of policies described above were derived for a given parametrization of the monetary policy rule and

for an exogenous LTV process. Now we go one step further and look at how FCLs affect the monetary policy frontier. In particular, we optimize the behavior of the monetary authority and analyze the trade-off it faces. Following much of the literature, the Taylor-like rule is assumed to respond to output $y_{t}$ and inflation $\pi_{t} \equiv P_{t} / P_{t-1}$

$$
\frac{R_{t}}{R}=\left(\frac{R_{t-1}}{R}\right)^{\gamma_{R}}\left[\left(\frac{\pi_{t}}{\pi}\right)^{\gamma_{\pi}}\left(\frac{y_{t}}{y}\right)^{\gamma_{y}}\right]^{1-\gamma_{R}}
$$


where variables without time subscripts indicate the steady-state values. We next look at the trade-off between stabilizing these two variables. To this aim, we construct efficient policy frontiers by finding optimal coefficients of the policy rule defined above for the policy loss function with a full spectrum of weights on output vs. inflation. In order to eliminate unrealistically volatile instruments, we introduce a cap on the standard deviation of the interest rate at 2.5 p.p. (annualized). More specifically, to obtain the monetary policy frontiers we solve the following sequence of optimization problems indexed by $\lambda \in[0,1]$

$$
\min _{\gamma_{R}, \gamma_{\pi}, \gamma_{y}}\left\{\lambda D\left(\pi_{t}\right)+(1-\lambda) D\left(y_{t}\right)\right\}
$$

subject to $D\left(R_{t}\right) \leq 0.25 / 4$, where $D\left(x_{t}\right)$ indicates the ergodic standard deviation of variable $x_{t}$.

The obtained policy frontiers both in the case of FCLs and DCLs are illustrated in Figure 3a, which plots the pairs of standard deviations of output and inflation corresponding to various values of $\lambda .^{6}$ The frontiers show that our earlier findings about the business cycle implications of FCLs are robust to policy reaction. In all cases, the economy is more volatile with foreign currency loans as the frontier under DCLs is closer to the origin than that for FCLs.

The results above point out that the presence of FCLs increases macroeconomic volatility and limits the effectiveness of monetary policy. Next, we check whether this problem can be resolved by introducing macroprudential policy. We consider two cases - a macroprudential policy that has the same objective as monetary policy (i.e. policies are coordinated), and the case when it follows its own target.

In the coordinated exercise both monetary and macroprudential policy have the same goal given by the loss function (16). Macroprudential policy uses as an instrument the LTV ratio. In contrast to monetary policy, there is no well-established practice about which variables macroprudential policy should respond to. We decided to model it as responding both to developments in the real and financial sector of the economy, represented by output and credit, respectively. For this experiment, the LTV ratio is no longer exogenous, but is assumed to follow

$$
\frac{m_{t}}{m}=\left(\frac{l_{t}}{l}\right)^{\gamma_{m l}}\left(\frac{y_{t}}{y}\right)^{\gamma_{m y}}
$$

where $l_{t}$ denotes total real loans. In order to eliminate an unrealistically volatile instrument, we introduce a cap on the standard deviation of the LTV ratio at 10 percentage points.

In the uncoordinated policy experiment monetary policy still minimizes (16), but macroprudential policy is supposed to minimize the variance of credit. This goal, while less sup-

\footnotetext{
${ }^{6}$ In practice, Figures ??-?? are produced by applying a fine grid for $\lambda$.
} 
portive for monetary authorities, seems more in line with the objectives currently set to macroprudential authorities.

The results of these simulations are presented on Figure 3c for an economy where all credit is denominated in foreign currency, and on Figure 3d for the case of DCLs only. Three findings stand out. First, coordinating monetary and macroprudential policy shifts the monetary policy frontiers substantially inwards. Both under FCLs and DCLs the frontier with coordinated macroprudential policy lies closer to the origin than the frontier without macroprudential policy. This means, in particular, that if the creation of FCLs raises macroeconomic volatility, introduction of macroprudential policy can bring it back down. However, a real test of the possibilities offered by macroprudential policy is to check whether it can prevent the deterioration of the trade-off provided that it was in place already before the creation of FCLs. The answer can be deduced from comparing the two frontiers with macroprudential policy presented on Figure 3b. Unfortunately, this being our second conclusion, this is not the case. The FCL frontier lies significantly more outwards than the DCL frontier. Our third conclusion is related to the case of non-coordinated policies. Both for DCLs and FCLs, the policy frontiers are very similar to those achievable with monetary policy alone. Of course, the policy is very effective in reducing the volatility of credit as it is its only target (not shown).

All in all, our findings show that if one treats the increase in macroeconomic volatility (and in particular the deterioration in the output-inflation volatility trade-off) resulting from FCLs as a problem, macroprudential policy does not seem to be a solution. If it follows the monetary policymakers' goal, it stabilizes the economy, but it cannot offset instability brought by the FCLs. If it follows its own objective, it barely shifts the frontier that is relevant to monetary policy.

\subsection{Welfare implications of foreign currency loans}

We next show how foreign currency loans affect agents' welfare. We do this by comparing the model-consistent utility for different shares $\eta_{L, \chi}$ of DCLs in households' portfolio. We report the results separately for patient and impatient households, as well as using aggregate welfare computed as follows (see e.g. Lambertini et al., 2013; Rubio and Carrasco-Gallego, 2014)

$$
U_{t}=\omega_{P}\left(1-\beta_{P}\right) U_{P, t}+\omega_{I}\left(1-\beta_{I}\right) U_{I, t}
$$

where $U_{P, t}$ and $U_{I, t}$ are second-order approximations to the lifetime utility of patient and impatient households, respectively. ${ }^{7}$

\footnotetext{
${ }^{7}$ Using the second-order approximation means that the first-order accurate movements in the loan portfolio composition on welfare are not taken into account, see Devereux and Sutherland (2011). This also implies
} 
Welfare is presented as consumption equivalent, defined as percent of lifetime consumption that households would be willing to forgo to have only domestic currency loans in their portfolio (with total loans unchanged). To make the findings easier to understand we proceded in three steps. First, we analyze a variant with only domestic monetary policy shocks existing in the economy. Next, we move to the case with only international risk premium (exchange rate) shocks. Finally, we show the welfare implications of FCLs in the complete stochastic environment, in which the economy is hit by all shocks.

Figure 4 shows the welfare effects of FCLs when domestic monetary policy is the only source of aggregate risk. It is intuitive that in such a case borrowers should dislike DCLs and prefer FCLs, since the latter generate less volatility in their consumption, housing and labor effort. Indeed, impatient agents' welfare can be raised by up to $0.18 \%$ if DCLs are substituted with FCLs. This comes at the expense of savers and hence aggregate welfare can be raised by only $0.13 \%$ in this case. Interestingly, the welfare function is non-monotonic as the maximum is obtained for a $13 \%$ share of DCLs in the household mortgage portfolio. The reason is intuitive. Monetary policy shocks affect not only the domestic interest rate, but also the exchange rate. Fluctuations in the former discourage borrowers from taking DCLs, while those of the latter strongly affect their balance sheets when FCLs are held. Our welfare function solves the trade-off problem generated by these two effects, but gives a clear preference to FCLs.

The opposite result obtains when only risk premium shocks are present. These move primarily the exchange rate. As evidenced in Figure 5, in this scenario an increase in FCLs always leads to lower welfare of borrowers as it means higher exposure of their balance sheets to exchange rate fluctuations. If only FCLs are taken, the aggregate welfare loss is equivalent to $1.3 \%$ of lifetime consumption compared to the DCL-only case. This number for impatient agents is even higher and amounts to almost $2 \%$.

Finally, we show the results for the complete stochastic environment. As presented in Figure 6, there is again an internal optimum. Total welfare is maximized for a DCL share of $87 \%$, but in fact the function is almost flat in the $70-100 \%$ region. However, for lower DCL shares welfare losses can be substantial, reaching $1.2 \%$ of lifetime consumption if agents hold only FCLs. For impatient agents the loss may attain 1.9\%. The similarity of Figures 5 and 6 suggests that risk premium shocks play the most important role in determining welfare effects of FCLs. This result clearly speaks in favor of holding a loan portfolio that primarily consists of domestic currency loans.

that the welfare evaluation presented in this section does not depend on the elasticity of substitution between domestic and foreign currency loans. 


\subsection{Using regulation to change the share of FCLs}

In the preceding two subsections we documented that a substantial share of FCLs may decrease the effectiveness of monetary policy and negatively affect welfare. A natural question arises whether some regulation can be used to reduce the share of FCLs and at what cost. To answer this question, we design two additional regulatory tools, whose aim is to change the composition of the loan portfolio, and use our model to show how they impact the economy. The presented experiments are motivated by the recent experience of several CEE countries, where the financial supervisory authorities implemented measures aimed at curbing foreign currency lending to households. The rationale for this regulation was usually to limit systemic risk in the banking sector. This kind of considerations are absent in our model, hence we cannot evaluate the potential benefits related to financial stability and focus instead on possible costs.

The first tool that we consider targets directly this proportion by setting the maximum share of DCLs in total loans $L_{H, t} / L_{t}$ to an exogenously defined value $\vartheta_{t}$. The second instrument works through the cost channel as it introduces a tax $\tau_{t}$ on foreign loans. This tax shows up in impatient households' budget constraint (3), raising the effective cost of FCLs, as well as in the collateral constraint (5), raising the repayment value of debt. These two alternative instruments are applied separately and in a non-stochastic environment.

First, we document how the economy reacts if macroprudential policy is used to permanently decrease the share of FCLs to $\vartheta_{t}$. The experiment assumes that the share of FCLs is permanently reduced from $50 \%$ (our benchmark equal to the share desired by households) to $45 \%$ (imposed by the regulator). The results depend on the degree of substitutability between DCLs and FCLs. If the two types of loans are perfectly substitutable $\left(\phi_{L}=\infty\right)$, the economy does not react to the intervention. Households simply substitute FCLs with DCLs and total lending as well as other variables remain unchanged. However, if FCLs and DCLs are imperfect substitutes $\left(\phi_{L}=6\right)$, the story becomes more interesting. Figure 7 presents the effects of this shock. Borrowers react to the lower imposed share of FCLs by increasing DCLs, though by less than they reduce FCLs. As a result, total loans decline. This leads to a reduction in residential investment. Even though consumption increases (crowding in effect), total output declines (by more in the short-run than in the long-run). Inflation initially goes up before eventually returning to the inflation target.

In the second experiment a tax $\tau_{t}>0$ is permanently imposed by the regulator. If domestic and foreign currency loans are perfectly substitutable, households eliminate FCLs from their portfolio completely and no other variables are affected. However, if loans are imperfect substitutes, the outcome is quite different. As Figure 8 shows, after such policy is applied, total loans decline, which leads to lower residential investment and lower consumption. Here, and in contrast to the quantitative restriction policy $\vartheta_{t}$, the imposition of a tax 
on FCLs increases debt servicing cost and hence a reduction in consumption of impatient households is stronger. Since patient households increase their consumption (crowding in), total consumption eventually goes up. Total output falls and its decline during the transition period is larger than in the long run. Inflation behaves similarly as in the first scenario.

The main conclusion from this section is as follows. Irrespective of the instrument, the transition to a new composition of FCLs and DCLs can result in an economic slowdown, which is costly. Since our framework does not include financial stability considerations, we cannot evaluate the potential gains of reducing the share of FCLs that are due to a decrease in systemic risk. However, we show that, for the considered ways of regulating foreign currency lending to be desired, these gains have to be large enough to compensate the associated costs.

\subsection{Currency conversion}

During the financial crisis exchange rates of many emerging markets depreciated sharply, raising the debt volume of FCLs expressed in domestic currency (being the main income currency) in countries like Hungary or Poland. In both of these economies a public debate started whether the affected borrowers should be bailed out. Hungary took several steps that ultimately led to full conversion of FCLs to DCLs, whereas the cost of this operation was shared between households and banks. Poland has been debating the issue for several years but no final decision has been made so far. The most far-reaching project was proposed by the Polish President and assumed full conversion of foreign currency mortgages to domestic currency at the original exchange rate. Such a solution would have charged the whole cost on the banking sector. The financial supervisory authority estimated the cost at up to PLN 67 bn or almost $5 \%$ of bank assets. In this section we simulate a similar scenario in our model and check how it affects the economy. It should however be noted that this scenario implicitly assumes that bank losses are immediately covered by their owners, i.e. patient households in our model. In other words, we only deal with redistribution between borrowers and savers, and do not take into account the potential impact of bank undercapitalization (or even bankruptcy) on the economy.

Our experiment consist of two parts. ${ }^{8}$ First, we generate a sharp depreciation of the exchange rate using a risk premium shock. We choose the shock size to generate a depreciation of almost 14\%, equal to what happened in Poland in the second half of 2008, i.e. following the Lehman Brothers collapse. This, on top of the usual business cycle implications (higher exports and inflation, lower imports) affects the economy via the FCL channel. As it is clear from the budget constraint of impatient households (3), they suffer a balance sheet loss as

\footnotetext{
${ }^{8}$ We also run the experiment assuming perfect substitution between DCLs and FCLs to ensure that the findings are robust to this parameter. The results are very similar.
} 
the FCLs they hold have to be repaid at the weaker exchange rate. The consequences can be observed in Figure 9 (dotted line). Consumption of impatient households drops sharply and their borrowing ability declines as their collateral constraint (5) tightens due to the depreciated exchange rate. Since in our model the losses incurred by borrowers imply gains for banks, consumption of patient households (bank owners) increases.

We next impose the currency conversion on the scenario discussed above, assuming that its entire cost is borne by the banks. Technically, we do it by generating a transfer payment from patient to impatient households, the size of which equals the loss incurred by the exchange rate depreciation, i.e. $T_{I, t}=\left(S_{t}-S_{t-1}\right)\left[(1+\tau) R_{F, t-1} L_{F, t-1}\right]$. Additionally, we set $\eta_{L, t}=1$, which modifies the loan composition preferred by borrowers to one with DCLs only. In contrast to the simulation presented in Section 4.4, this implies that impatient households agree to the conversion, making this aspect of the operation neutral in terms of welfare. The simulation is presented with solid line in Figure 9. The resulting wealth transfer is large, amounting to about $7.5 \%$ of GDP. Clearly, the negative consequences of the depreciation for borrowers are to a large extent reduced. This happens at the expense of patient households, but their losses are small relative to those incurred by borrowers when there is no currency conversion. Foreign lending falls to zero, but is quickly substituted by domestic loans.

These findings are consistent with a formal evaluation of welfare effects calculated for both types of households, which we present in Table 6. The depreciation entails a heavy loss for borrowers, equivalent to $1.4 \%$ of their lifetime consumption. When the financial loss is offset by the transfer, the welfare cost declines to $0.27 \%$. Of course, this happens at the expense of bank owners, whose gain from the depreciation shrinks from $1.24 \%$ to $0.04 \%$ of lifetime consumption. Total welfare is lowered by the depreciation, as the loss incurred by borrowers outweights the gains of bank owners. The currency conversion improves this outcome somewhat as wealth is shifted towards households with a higher marginal utility. However, even after the transfer, aggregate welfare is lower than in the case of no exchange rate shock.

\section{Conclusions}

Foreign currency loans play an important role in several countries, both advanced and emerging ones. They affect the economy through several channels. First, they are a source of exchange rate risk for borrowers. Second, empirical evidence shows that they weaken monetary transmission.

In this paper we analyze the role of foreign currency lending in a structural economic model. To this end we construct a small open economy DSGE model with financial frictions in the form of collateral constraints, where households can take loans in domestic and foreign currency. In this framework we test how the presence of foreign currency lending affects the 
transmission of monetary and macroprudential policy. Furthermore, we analyze the welfare implications of foreign currency loans.

Our main findings are as follows. First, foreign currency loans impair the transmission of monetary policy but do not affect so much the effectiveness of macroprudential policy. Importantly, the output-inflation volatility trade-off clearly deteriorates when households are allowed to borrow in foreign currency, even when both macroeconomic policies cooperate. Second, we find that FCLs increase aggregate welfare when domestic interest rate shocks are strong and decrease it when risk premium (exchange rate) shocks dominate. Under a realistic calibration of the stochastic environment, FCLs are welfare reducing. This is a remarkable result given that we abstract away from financial stability aspects, which would make the presence of FCLs even less desirable. Third, we show that restoring the effectiveness of monetary policy or improving welfare through FCL discriminating regulation may have a (mainly short-run) negative impact on the economy. Fourth, we simulate a scenario under which the government responds to currency depreciation by enforcing a conversion of FCLs to DCLs. We show that such an intervention benefits the borrowers but hurts bank owners, and has positive aggregate consequences. Naturally, this conclusion could be reversed if we took into account the impact of exchange conversion on bank capital in a richer modeling environment where banks are not automatically recapitalized by their owners.

While this paper tackled a number of important topics related to foreign currency lending, several other issues remain to be analyzed. This includes in particular endogenizing the choice of FCLs (for instance by introducing a portfolio choice as in Kolasa (2016)) or analyzing the impact of FCLs for financial stability (for instance by introducing housing and banking default). While not crucial for the topics discussed here, these problems are certainly interesting and we leave them for further research. 


\section{References}

Brzoza-Brzezina, Michał, Pascal Jacquinot, and Marcin Kolasa (2014) 'Can We Prevent Boom-Bust Cycles During Euro Area Accession?' Open Economies Review 25(1), 35-69

Brzoza-Brzezina, Michał, Tomasz Chmielewski, and Joanna Niedźwiedzińska (2010) 'Substitution between domestic and foreign currency loans in Central Europe. Do central banks matter?' Working Paper Series 1187, European Central Bank

Coenen, Günter, Peter McAdam, and Roland Straub (2008) 'Tax reform and labour-market performance in the euro area: A simulation-based analysis using the New Area-Wide Model.' Journal of Economic Dynamics and Control 32(8), 2543-2583

Dell'Ariccia, Giovanni, Deniz Igan, Luc Laeven, and Hui Tong (2016) 'Credit booms and macrofinancial stability.' Economic Policy 31(86), 299-355

Devereux, Michael B., and Alan Sutherland (2011) 'Country Portfolios In Open Economy Macro Models.' Journal of the European Economic Association 9(2), 337-369

Devereux, Michael B., and James Yetman (2010) 'Leverage Constraints and the International Transmission of Shocks.' Journal of Money, Credit and Banking 42(s1), 71-105

Dhyne, Emmanuel, Luis J. Álvarez, Herve Le Bihan, Giovanni Veronese, Daniel Dias, Johannes Hoffmann, Nicole Jonker, Patrick Lünnemann, Fabio Rumler, and Jouko Vilmunen (2006) 'Price changes in the euro area and the United States: Some facts from individual consumer price data.' Journal of Economic Perspectives 20(2), 171-192

Dübel, Hans-Joachim, and Simon Walley (2010) 'Regulation of foreign currency mortgage loans: The case of transition countries in Central and Eastern Europe.' World Bank Other Operational Studies 12943, The World Bank

Egert, Balazs, Peter Backe, and Tina Zumer (2007) 'Private-sector credit in Central and Eastern Europe: New (over)shooting stars?' Comparative Economic Studies 49(2), 201231

Elekdag, Selim, and Ivan Tchakarov (2007) 'Balance sheets, exchange rate policy, and welfare.' Journal of Economic Dynamics and Control 31(12), 3986-4015

Elenev, Vadim, Tim Landvoigt, and Stijn Van Nieuwerburgh (2016) 'Phasing out the GSEs.' Journal of Monetary Economics 81(C), 111-132 
ESRB (2011) 'Recommendation of the European Systemic Risk Board of 21 september 2011 on lending in foreign currencies.' Recommendation ESRB/2011/1, European Systemic Risk Board

Gerali, Andrea, Stefano Neri, Luca Sessa, and Federico M. Signoretti (2010) 'Credit and banking in a DSGE model of the euro area.' Journal of Money, Credit and Banking 42(s1), 107-141

Gertler, Mark, Simon Gilchrist, and Fabio M. Natalucci (2007) 'External Constraints on Monetary Policy and the Financial Accelerator.' Journal of Money, Credit and Banking $39(2-3), 295-330$

Iacoviello, Matteo (2005) 'House prices, borrowing constraints, and monetary policy in the business cycle.' American Economic Review 95(3), 739-764

Iacoviello, Matteo, and Stefano Neri (2010) 'Housing market spillovers: Evidence from an estimated DSGE model.' American Economic Journal: Macroeconomics 2(2), 125-64

Justiniano, Alejandro, and Bruce Preston (2010) 'Monetary policy and uncertainty in an empirical small open-economy model.' Journal of Applied Econometrics 25(1), 93-128

Kiyotaki, Nobuhiro, and John Moore (1997) 'Credit cycles.' Journal of Political Economy $105(2), 211-48$

Kolasa, Marcin (2016) 'Equilibrium foreign currency mortgages.' mimeo, Narodowy Bank Polski

Kolasa, Marcin, and Giovanni Lombardo (2014) 'Financial Frictions and Optimal Monetary Policy in an Open Economy.' International Journal of Central Banking 10(1), 43-94

Lambertini, Luisa, Caterina Mendicino, and Maria Teresa Punzi (2013) 'Leaning against boom-bust cycles in credit and housing prices.' Journal of Economic Dynamics and Control $37(8), 1500-1522$

Lim, C., F. Columba, A. Costa, P. Kongsamut, A. Otani, M.Saiyid, T.Wezel, and X.WU (2011) 'Macroprudential policy: What instruments and how to use them? Lessons from country experiences.' IMF Working Papers 11/238, International Monetary Fund

Macias, Pawel, and Krzysztof Makarski (2013) 'Stylizowane fakty o cenach konsumenta w Polsce.' Materiały i Studia 268, Narodowy Bank Polski 
Magud, Nicolas E., Carmen M. Reinhart, and Esteban R. Vesperoni (2014) 'Capital inflows, exchange rate flexibility, and credit booms.' Review of Development Economics 18(3), 415430

Mendicino, Caterina, Kalin Nikolov, Javier Suarez, and Dominik Supera (2016) 'Optimal dynamic capital requirements.' mimeo, European Central Bank

Poutineau, Jean-Christophe, and Gauthier Vermandel (2015) 'Cross-border banking flows spillovers in the Eurozone: Evidence from an estimated DSGE model.' Journal of Economic Dynamics and Control 51, 378-403

Rosenberg, Christoph, and Marcel Tirpák (2009) 'Determinants of foreign currency borrowing in the new member states of the EU.' Czech Journal of Economics and Finance (Finance a uver) 59(3), 216-228

Rubio, Margarita, and José A. Carrasco-Gallego (2014) 'Macroprudential and monetary policies: Implications for financial stability and welfare.' Journal of Banking and Finance 49, 326-336

Ruge-Murcia, Francisco (2012) 'Estimating nonlinear dsge models by the simulated method of moments: With an application to business cycles.' Journal of Economic Dynamics and Control 36(6), 914-938

SNB (2013) 'CHF lending monitor.' Technical Report 2013:Q2, Swiss National Bank

Tille, Cedric, and Eric van Wincoop (2010) 'International capital flows.' Journal of International Economics 80(2), 157-175

Yesin, Pinar (2013) 'Foreign currency loans and systemic risk in Europe.' Federal Reserve Bank of St. Louis Review 93(3), 219-236 


\section{Tables and figures}

Table 1: Steady state ratios

\begin{tabular}{lc}
\hline Steady state ratio & Value \\
\hline Share of government expenditure & 0.181 \\
Import of consumer goods to output ratio & 0.11 \\
Import of capital investment goods to output ratio & 0.14 \\
Residential investment to output ratio & 0.028 \\
Capital investment to output ratio & 0.177 \\
Share of FCLs in total loans & 0.5 \\
Hours worked & 0.32 \\
Housing wealth to output ratio (annual) & 1.3 \\
Debt to output ratio (annual) & 0.75 \\
Spread (annualized) & 0.019 \\
Relative consumption of impatient HHs & 0.77 \\
\hline
\end{tabular}


Table 2: Calibration - parameters

\begin{tabular}{|c|c|c|}
\hline Parameter & Value & Description \\
\hline$\beta_{P}$ & 0.993 & Discount factor, patient $\mathrm{HHs}$ \\
\hline$\beta_{I}$ & 0.985 & Discount factor, impatient HHs \\
\hline$\delta_{\chi}$ & 0.0054 & Housing stock depreciation rate \\
\hline$\delta_{k}$ & 0.02 & Capital stock depreciation rate \\
\hline$\omega_{I}$ & 0.75 & Share of impatient HHs \\
\hline$A_{\chi}$ & 0.56 & Weight on housing in utility function \\
\hline$A_{n}$ & 110 & Weight on labor in utility function \\
\hline$\sigma_{n}$ & 2 & Inverse of Frisch elasticity of labor supply \\
\hline$\xi$ & 0.75 & Degree of external habit formation in consumption \\
\hline$\theta_{w}$ & 0.75 & Calvo probability for wages \\
\hline$\phi_{n}$ & 6 & Elasticity of substitution btw. labor of patient and impatient $\mathrm{HHs}$ \\
\hline$\tau_{I}$ & 0.35 & Transfers to impatient HHs (relative to government spending) \\
\hline$\mu$ & 1.2 & Steady state product markup \\
\hline$\theta_{H}$ & 0.75 & Calvo probability for domestic prices \\
\hline$\theta_{F}$ & 0.75 & Calvo probability for import prices \\
\hline$\theta_{H}^{*}$ & 0.75 & Calvo probability for export prices \\
\hline$\alpha$ & 0.32 & Output elasticity with respect to capital \\
\hline$\kappa_{k}$ & 0.337 & Capital investment adjustment cost \\
\hline$\kappa_{\chi}$ & 11.83 & Housing investment adjustment cost \\
\hline$\mu_{L}$ & 1.0047 & Loan markup \\
\hline$m$ & 0.85 & Steady state LTV ratio \\
\hline$\eta_{L}$ & 0.5 & Share of domestic currency loans in total loans \\
\hline$\phi_{L}$ & 6 & Elasticity of substitution btw. domestic and foreign currency loans \\
\hline$\pi$ & 1.005 & Steady state inflation \\
\hline$\varrho$ & 0.02 & Elasticity of risk premium wrt. foreign debt \\
\hline$\gamma_{R}$ & 0.75 & Interest rate smoothing in Taylor rule \\
\hline$\gamma_{\pi}$ & 2 & Response to inflation in Taylor rule \\
\hline$\gamma_{y}$ & 0.5 & Response to output in Taylor rule \\
\hline$\eta_{c}$ & 0.816 & Share of domestic goods in consumption basket \\
\hline$\eta_{k}$ & 0.205 & Share of domestic goods in investment \\
\hline$\phi_{y}^{*}$ & 1.5 & Price elasticity of exports \\
\hline$\phi_{c}$ & 1.5 & Elasticity of substitution btw. home and foreign consumption goods \\
\hline$\phi_{k}$ & 1.5 & Elasticity of substitution btw. home and foreign investment goods \\
\hline
\end{tabular}


Table 3: Calibration - stochastic shocks

\begin{tabular}{ccl}
\hline Parameter & Value & Description \\
\hline$\rho_{z}$ & 0.92 & Productivity shock - autocorrelation \\
$\sigma_{z}$ & 0.007 & Productivity shock - standard deviation \\
$\rho_{g}$ & 0.63 & Government spending shock - autocorrelation \\
$\sigma_{g}$ & 0.011 & Government spending shock - standard deviation \\
$\rho_{\rho}$ & 0.71 & Risk premium shock - autocorrelation \\
$\sigma_{\rho}$ & 0.004 & Risk premium shock - standard deviation \\
$\rho_{\eta_{L}}$ & 0.999 & Shock to share of DCLs - autocorrelation \\
$\sigma_{\eta_{L}}$ & 0.003 & Shock to share of DCLs - standard deviation \\
$\sigma_{R}$ & 0.002 & Monetary shock - standard deviation \\
$\rho_{y}^{*}$ & 0.91 & Foreign output - autocorrelation \\
$\sigma_{y}^{*}$ & 0.006 & Foreign output - standard deviation \\
$\rho_{\pi}^{*}$ & 0.55 & Foreign inflation - autocorrelation \\
$\sigma_{\pi}^{*}$ & 0.002 & Foreign inflation - standard deviation \\
$\rho_{R}^{*}$ & 0.9 & Foreign interest rate - autocorrelation \\
$\sigma_{R}^{*}$ & 0.001 & Foreign interest rate - standard deviation \\
$r\left(\varepsilon_{\pi}^{*}, \varepsilon_{y}^{*}\right)$ & 0.48 & Correlation of residuals from foreign inflation and output eq. \\
$r\left(\varepsilon_{\pi}^{*}, \varepsilon_{R}^{*}\right)$ & 0.38 & Correlation of residuals from foreign inflation and interest rate eq. \\
$r\left(\varepsilon_{R}^{*}, \varepsilon_{y}^{*}\right)$ & 0.73 & Correlation of residuals from foreign interest rate and output eq. \\
\hline
\end{tabular}

Table 4: Moment matching

\begin{tabular}{lcccccc}
\hline \multirow{2}{*}{ Variable } & \multicolumn{3}{c}{ Standard dev. } & Autocorrelation & \multicolumn{2}{c}{ Corr. with output } \\
\cline { 2 - 7 } & Data & Model & Data & Model & Data & Model \\
\hline Output & 1.3 & 0.95 & 0.91 & 0.93 & 1.00 & 1.00 \\
Consumption & 0.95 & 1.17 & 0.82 & 0.91 & 0.74 & 0.5 \\
Non-Residential investment & 5.96 & 6.13 & 0.94 & 0.92 & 0.92 & 0.38 \\
Residential investment & 5.11 & 5.3 & 0.82 & 0.99 & 0.67 & 0.61 \\
Inflation & 0.45 & 0.49 & 0.44 & 0.84 & 0.55 & -0.71 \\
Interest rate & 1.7 & 2.12 & 0.92 & 0.87 & 0.60 & -0.83 \\
DCLs & 8.97 & 8.95 & 0.88 & 0.90 & 0.55 & 0.13 \\
FCLs & 9.84 & 10.04 & 0.90 & 0.85 & 0.21 & 0.10 \\
Real exchange rate & 7.15 & 2.16 & 0.79 & 0.70 & -0.25 & 0.09 \\
\hline
\end{tabular}

Note: All variables are quarterly data for Poland for the period 2000-2012, detrended with the Hodrick-Prescott filter. Source: Eurostat, NBP. 
Table 5: Model-implied moments for various shares of FCLs

\begin{tabular}{lcccccc}
\hline \multirow{2}{*}{ Variable } & \multicolumn{3}{c}{ Standard dev. } & \multicolumn{3}{c}{ Corr. with output } \\
\cline { 2 - 7 } & FCL: 0\% & FCL: 50\% & FCL: 100\% & FCL: 0\% & FCL: 50\% & FCL: 100\% \\
\hline Output & 0.96 & 0.95 & 1.01 & 1.00 & 1.00 & 1.00 \\
Consumption & 0.98 & 1.17 & 2.17 & 0.55 & 0.50 & 0.50 \\
Non-Residential investment & 6.92 & 6.13 & 6.67 & 0.30 & 0.38 & 0.17 \\
Residential investment & 5.15 & 5.3 & 6.05 & 0.63 & 0.61 & 0.51 \\
Inflation & 0.49 & 0.49 & 0.49 & -0.69 & -0.71 & -0.67 \\
Interest rate & 2.09 & 2.12 & 2.29 & -0.87 & -0.83 & -0.65 \\
DCLs & 8.28 & 8.95 & - & 0.11 & 0.13 & - \\
FCLs & - & 10.04 & 13.37 & - & 0.10 & 0.34 \\
Real exchange rate & 1.77 & 2.16 & 2.78 & 0.28 & 0.09 & -0.19 \\
\hline
\end{tabular}

Table 6: Welfare implications of the FCL conversion scenario

\begin{tabular}{cccc}
\hline & Impatient & Patient & Total \\
\hline Depreciation & -1.43 & 1.24 & -.77 \\
Depreciation + conversion & -0.27 & 0.04 & -0.20 \\
\hline Note: Welfare gains are expressed in per cent of steady state consumption.
\end{tabular}

Figure 1: Foreign Currency Loans and Monetary Policy
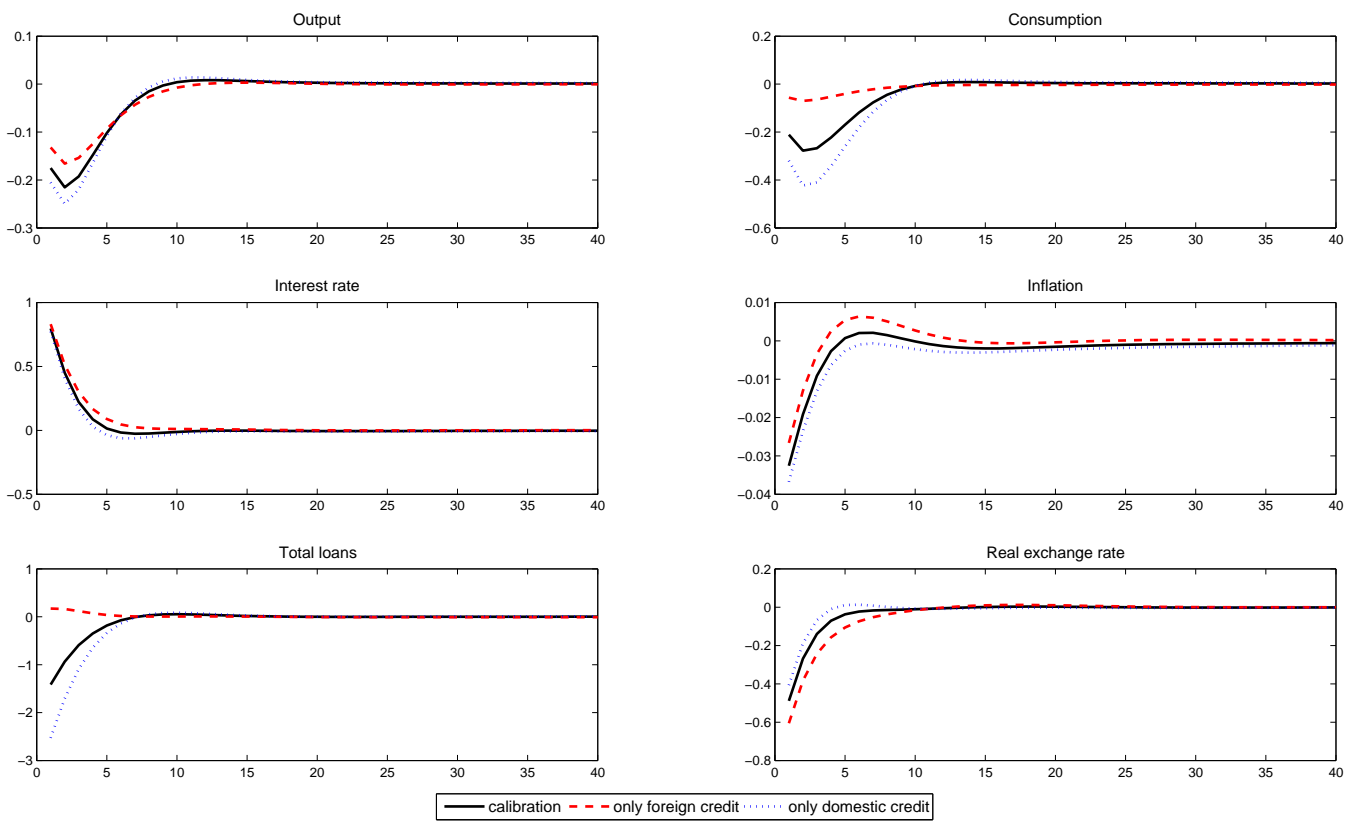

Note: The figure presents the impulse responses to a monetary policy shock for various shares of FCLs. All variables are expressed in per cent deviations from the steady state. 
Figure 2: Foreign Currency Loans and Macroprudential Policy
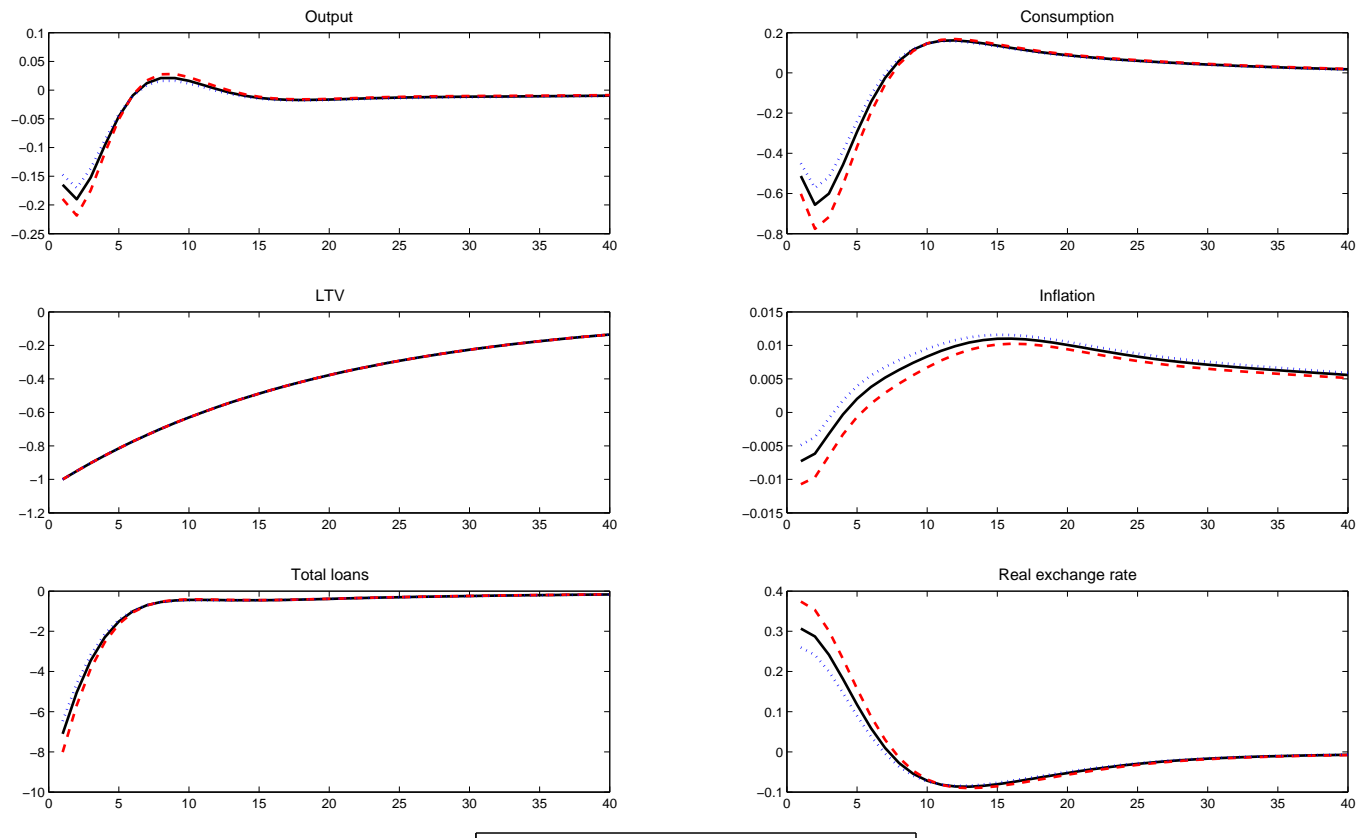

Note: The figure presents impulse responses to a macroprudential policy shock for various shares of FCLs. All variables are expressed as per cent deviations from the steady state.

Figure 3: Efficient policy frontiers
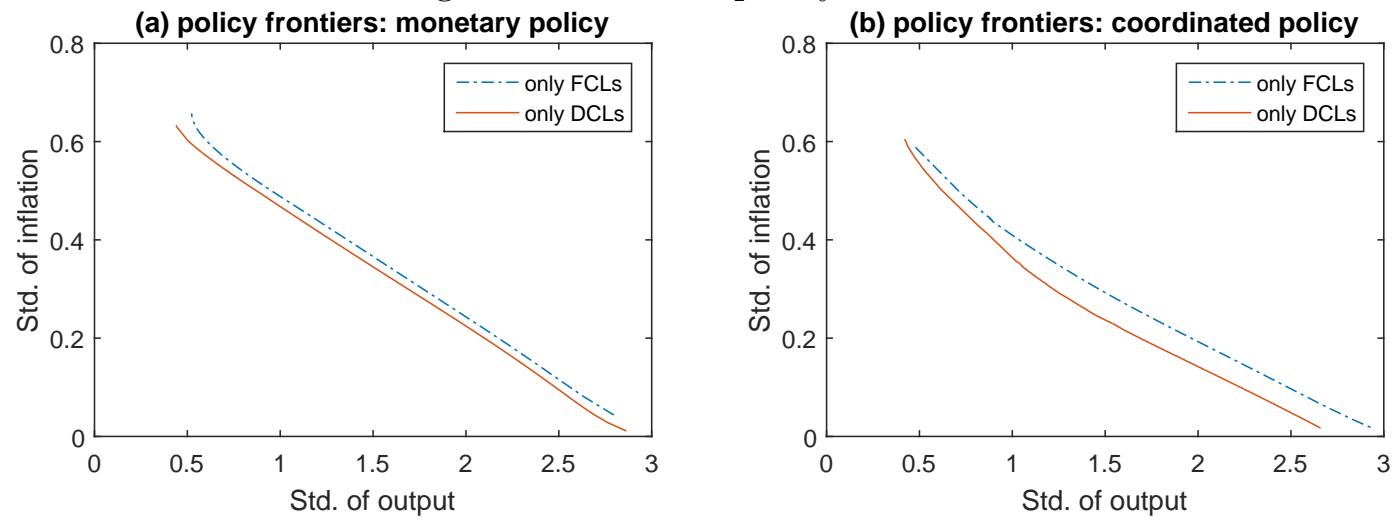

(c) policy frontiers: FCLs
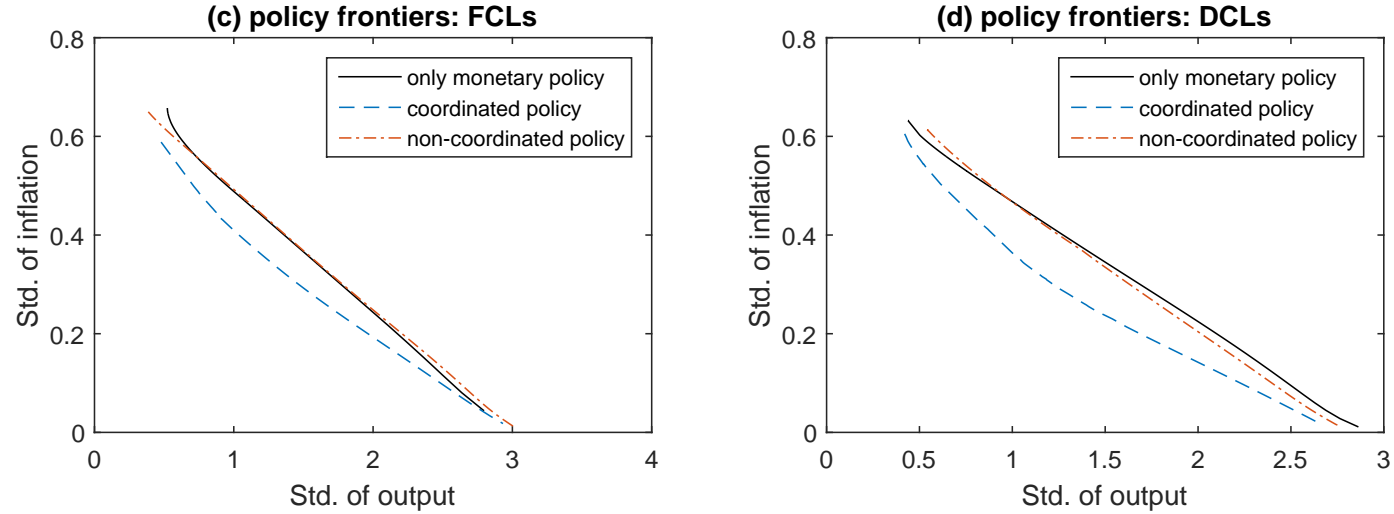

Note: The figure presents efficient policy frontiers for monetary policy, coordinated monetary and macroprudential policy and non-coordinated monetary and macroprudential policy. The frontiers are calculated for economies with only domestic or only foreign currency loans. 
Figure 4: Welfare effects of domestic monetary policy shocks

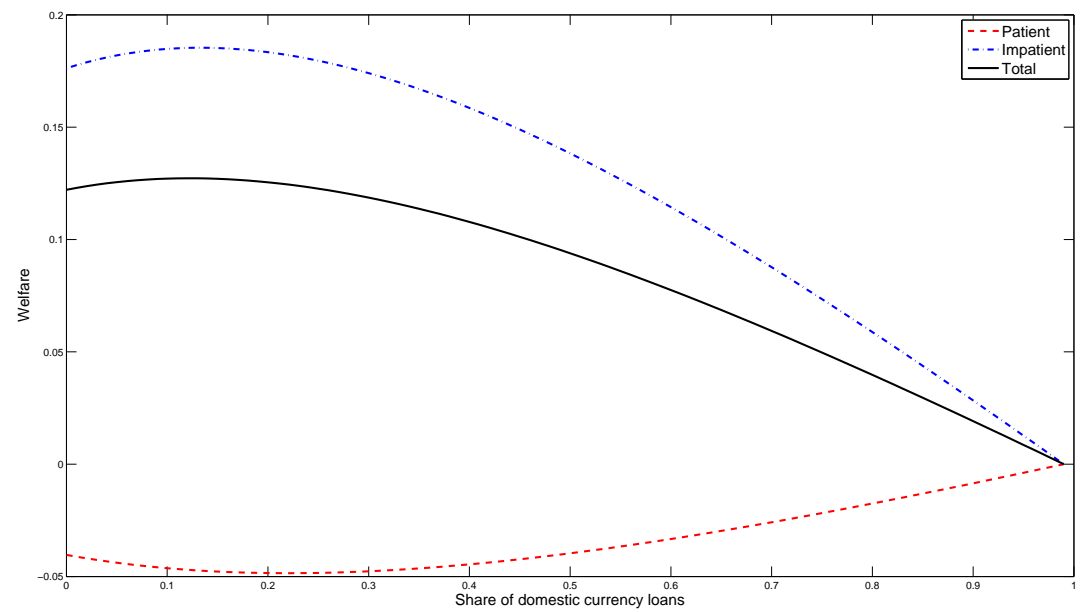

Note: The figure presents welfare implications of various shares of FCLs relative to welfare with domestic loans only. The differences are expressed as per cent of steady state consumption.

Figure 5: Welfare effects of risk premium shocks

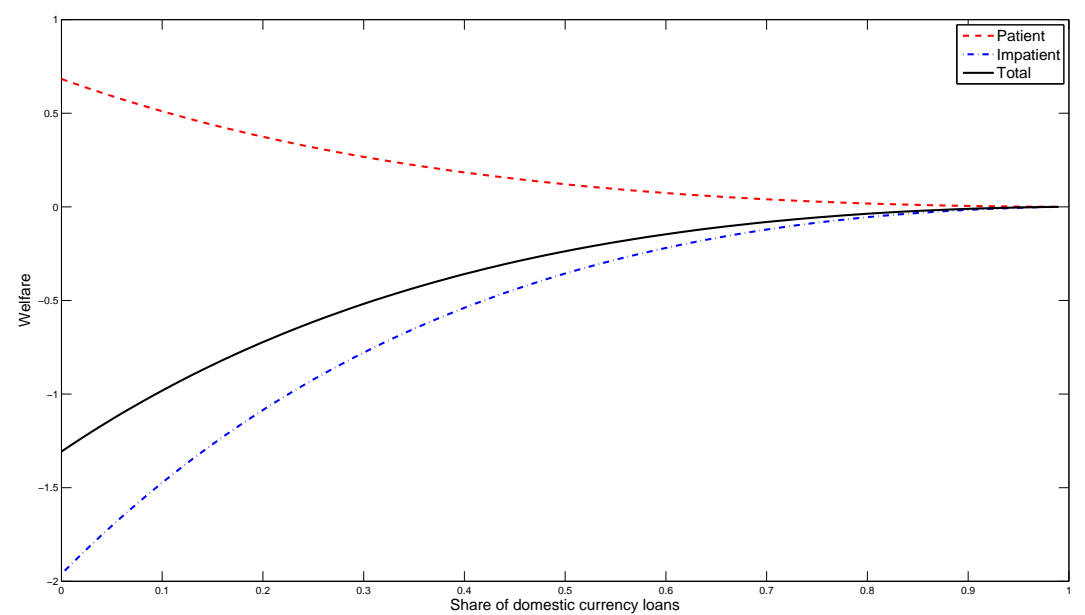

Note: The figure presents welfare implications of various shares of FCLs relative to welfare with domestic loans only. The differences are expressed as per cent of steady state consumption. 
Figure 6: Welfare effects of full composition of shocks

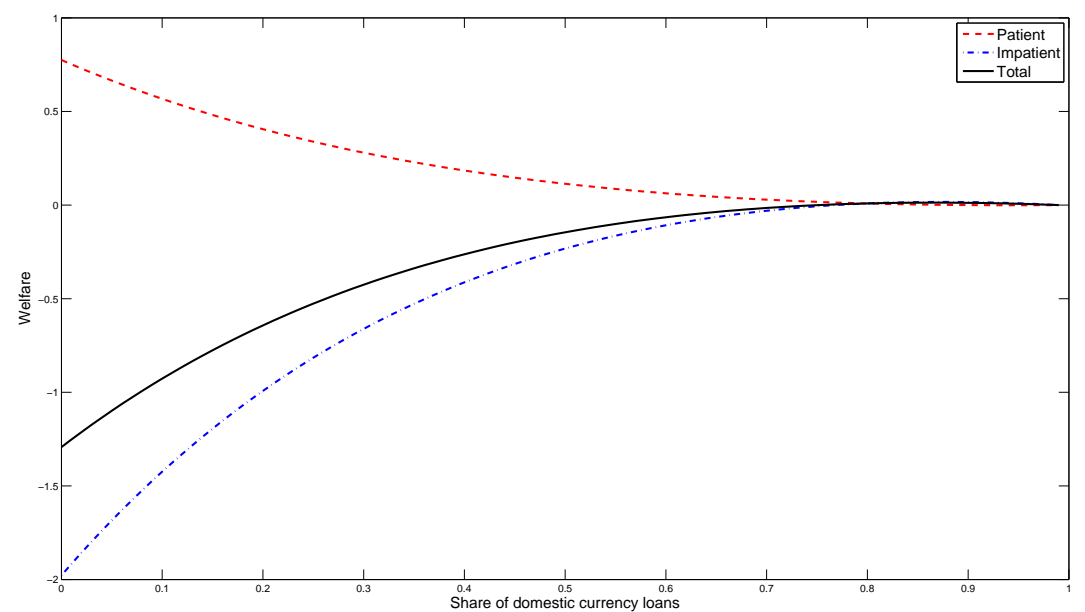

Note: The figure presents welfare implications of various shares of FCLs relative to welfare with domestic loans only. The differences are expressed as per cent of steady state consumption.

Figure 7: The effects of FCL discrimination under imperfect substitution
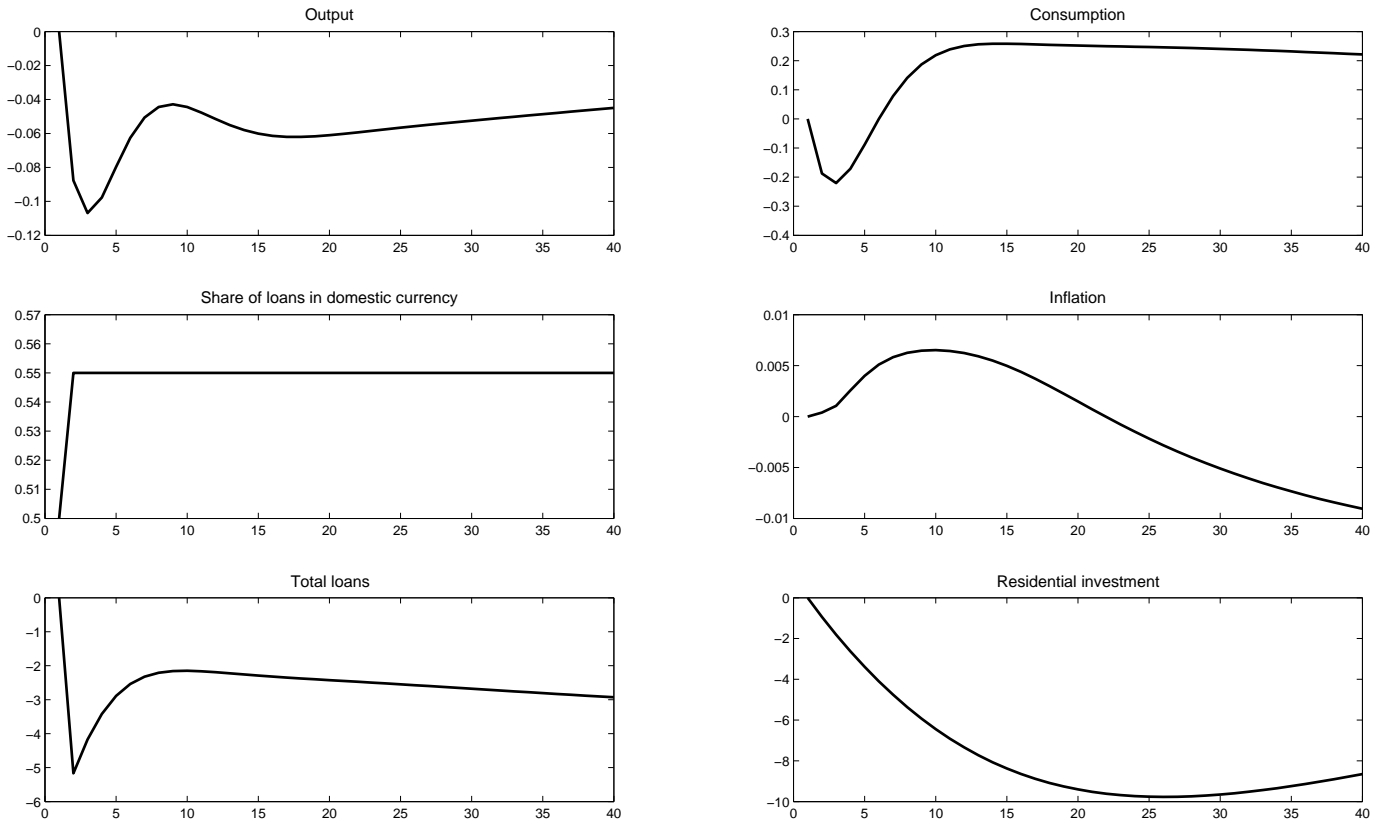

Note: The figure presents the impulse responses to a regulatory policy that restricts the share of FCLs. All variables are expressed as per cent deviations from the initial steady state. 
Figure 8: The effects of tax on FCL under imperfect substitution
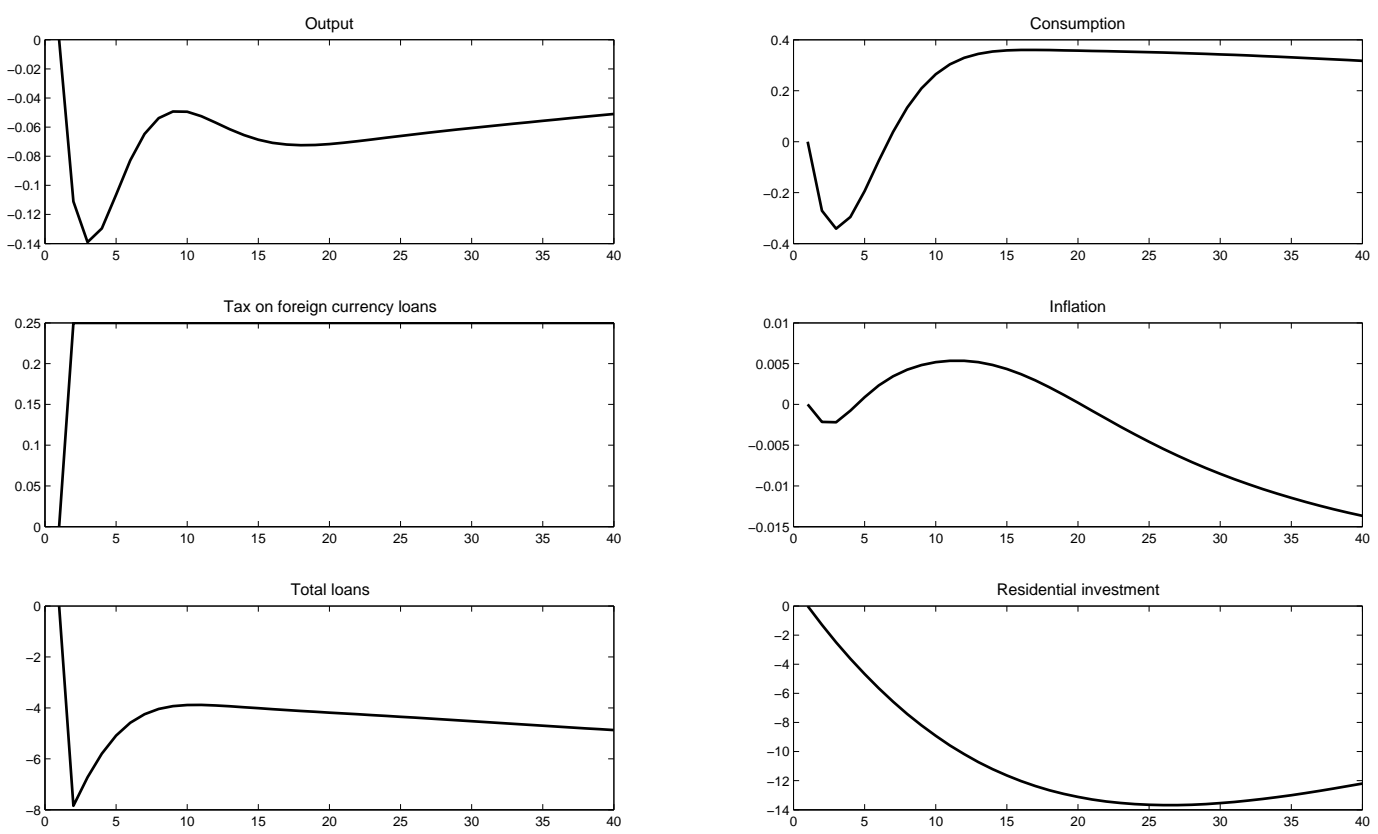

Note: The figure presents the impulse responses to a regulatory policy that introduces a tax on FCLs. All variables are expressed as per cent deviations from the initial steady state.

Figure 9: The currency conversion scenario
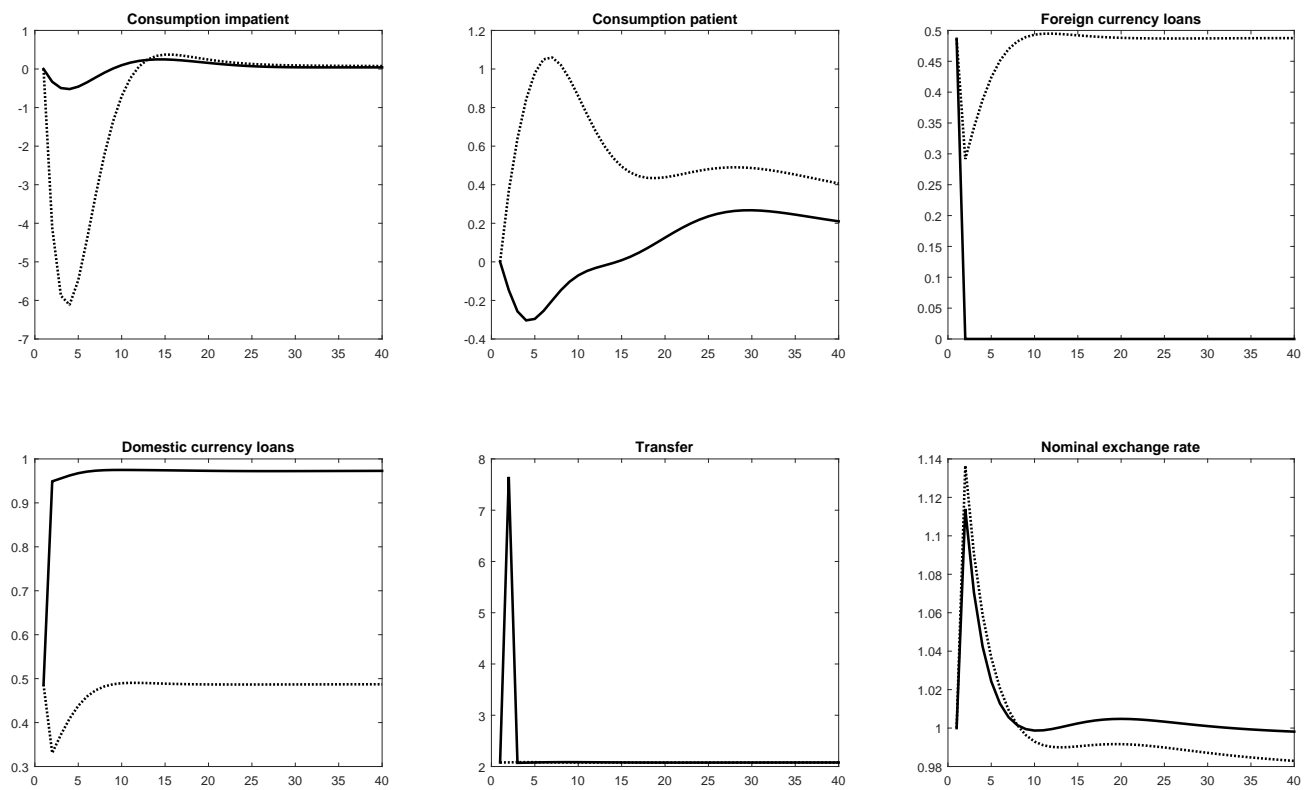

Note: Consumption is expressed in per cent deviations from steady state, loans and transfers are in per cent of GDP, the nominal exchange rate is normalized to unity in the initial steady state. The dotted line presents the consequences of currency depreciation. The sold line depicts the complete scenario of depreciation followed by currency conversion. 


\section{Appendix: List of model equations}

In this appendix we present a full list of equations making up our model. Lower-case letters are the real counterparts of the nominal variables defined in section 2. As regards the variables not showing up in the main text and not explicitly defined below, $q_{t} \equiv \frac{S_{t} P_{t}^{*}}{P_{t}}$ is the real exchange rate, $\pi_{t} \equiv \frac{P_{t}}{P_{t-1}}$ is the inflation rate, $\Theta_{t}$ is the Lagrange multiplier on the collateral constraint, $i_{\chi, t}$ and $i_{k, t}$ denote residential and capital investment and $g_{t}$ is government spending. The variables without time subscripts denote the steady state.

\section{Households}

Marginal utilities (for $i=\{I, P\}$ )

$$
u_{i, t}=\left(c_{i, t}-\xi c_{i, t-1}\right)^{-\sigma_{c}}
$$

Euler equation for patient households

$$
u_{P, t}=\beta_{P} \mathbb{E}_{t}\left\{u_{P, t+1} \pi_{t+1}^{-1}\right\} R_{t}
$$

Impatient households' budget constraint

$$
\begin{aligned}
c_{I, t}+p_{\chi, t}\left(\chi_{I, t}-\left(1-\delta_{\chi}\right) \chi_{I, t-1}\right)+R_{H, t-1} l_{H, t-1} \pi_{t}^{-1}+ \\
q_{t}\left(1+\tau_{t-1}\right) R_{F, t-1}\left(\pi_{t}^{*}\right)^{-1} l_{F, t-1}=w_{I, t} n_{I, t}+l_{t}+t_{I, t}
\end{aligned}
$$

Collateral constraint

$$
R_{H, t} l_{H, t}+\left(1+\tau_{t}\right) R_{F, t} l_{F, t} \mathbb{E}_{t}\left\{q_{t+1} \frac{\pi_{t+1}}{\pi_{t+1}^{*}}\right\}=m_{t}\left(1-\delta_{\chi}\right) \mathbb{E}_{t}\left\{p_{\chi, t+1} \pi_{t+1} \chi_{I, t}\right\}
$$

Euler equations for impatient households

$$
\begin{aligned}
& u_{I, t}=\left(\frac{l_{H, t}}{\eta_{L, t} l_{t}}\right)^{\frac{1}{\phi_{L}}}\left(\beta_{I} \mathbb{E}_{t}\left\{\frac{u_{I, t+1}}{\pi_{t+1}}\right\} R_{H, t}+\Theta_{t} R_{H, t}\right) \\
& u_{I, t}=\left(\frac{q_{t} l_{F, t}}{\left(1-\eta_{L, t}\right) l_{t}}\right)^{\frac{1}{\phi_{L}}}\left(\beta_{I} \mathbb{E}_{t}\left\{u_{I, t+1} \frac{q_{t+1}}{q_{t} \pi_{t+1}^{*}}\right\} R_{F, t}+\Theta_{t}\left(1+\tau_{t}\right) R_{F, t} \mathbb{E}_{t}\left\{\frac{q_{t+1}}{q_{t}} \frac{\pi_{t+1}}{\pi_{t+1}^{*}}\right\}\right)
\end{aligned}
$$

Loan aggregator

$$
l_{t}=\left[\eta_{L, t}^{\frac{1}{\phi_{L}}} l_{H, t}^{\frac{\phi_{L}-1}{\phi_{L}}}+\left(1-\eta_{L, t}\right)^{\frac{1}{\phi_{L}}}\left(q_{t} l_{F, t}\right)^{\frac{\phi_{L}-1}{\phi_{L}}}\right]^{\frac{\phi_{L}}{\phi_{L}-1}}
$$


Housing Euler equations

$$
\begin{aligned}
u_{P, t} p_{\chi, t}= & A_{\chi} \chi_{P, t}^{-\sigma_{\chi}}+\beta_{P}\left(1-\delta_{\chi}\right) \mathbb{E}_{t}\left\{u_{P, t+1} p_{\chi, t+1}\right\} \\
u_{I, t} p_{\chi, t}= & A_{\chi} \chi_{I, t}^{-\sigma_{\chi}}+\beta_{I}\left(1-\delta_{\chi}\right) \mathbb{E}_{t}\left\{u_{I, t+1} p_{\chi, t+1}\right\} \\
& +\Theta_{t} m_{t}\left(1-\delta_{\chi}\right) \mathbb{E}_{t}\left\{p_{\chi, t+1} \pi_{t+1}\right\}
\end{aligned}
$$

Capital Euler equation

$$
u_{P, t} p_{k, t}=\beta_{P} E_{t}\left\{u_{P, t+1}\left[\left(1-\delta_{k}\right) p_{k, t+1}+r_{k, t+1}\right]\right\}
$$

Total consumption

$$
c_{t}=\omega_{I} c_{I, t}+\left(1-\omega_{I}\right) c_{P, t}
$$

\section{Labor market}

Optimal wage set by reoptimizing households (for $i=\{I, P\}$ )

$$
\left(\tilde{w}_{i, t}\right)^{1+\sigma_{n} \frac{\mu_{w}}{\mu_{w}-1}}=\frac{\Omega_{w, i, t}}{\Upsilon_{w, i, t}}
$$

Auxiliary functions for optimal wages (for $i=\{I, P\}$ )

$$
\begin{gathered}
\Omega_{w, i, t}=\mu_{w} A_{n}\left(w_{i, t}\right)^{\frac{\mu_{w}}{\mu_{w}-1}\left(1+\sigma_{n}\right)} n_{i, t}^{1+\sigma_{n}}+\beta_{i} \theta_{w} \mathbb{E}_{t}\left\{\left(\frac{\pi}{\pi_{t+1}}\right)^{\frac{\mu_{w}}{1-\mu_{w}}\left(1+\sigma_{n}\right)} \Omega_{w, i, t+1}\right\} \\
\Upsilon_{w, i, t}=u_{i, t}\left(w_{i, t}\right)^{\frac{\mu_{w}}{\mu_{w}-1}} n_{i, t}+\beta_{i} \theta_{w} \mathbb{E}_{t}\left\{\left(\frac{\pi}{\pi_{t+1}}\right)^{\frac{1}{1-\mu_{w}}} \Upsilon_{w, i, t+1}\right\}
\end{gathered}
$$

Wage index (for $i=\{I, P\})$

$$
w_{i, t}^{\frac{1}{1-\mu_{w}}}=\theta_{w}\left(w_{i, t-1} \frac{\pi}{\pi_{t}}\right) \frac{1}{1-\mu_{w}}+\left(1-\theta_{w}\right) \tilde{w}_{i, t}^{\frac{1}{1-\mu_{w}}}
$$

Labor demand (for $i=\{I, P\}$ )

$$
n_{i, t}=\left(\frac{w_{i, t}}{w_{t}}\right)^{-\phi_{n}} n_{t}
$$


Aggregate wage

$$
w_{t}=\left[\omega_{I} w_{I, t}^{1-\phi_{n}}+\left(1-\omega_{I}\right) w_{P, t}^{1-\phi_{n}}\right]^{\frac{1}{1-\phi_{n}}}
$$

\section{Capital and housing producers}

Capital accumulation

$$
k_{t}=\left(1-\delta_{k}\right) k_{t-1}+\left(1-\frac{\kappa_{k}}{2}\left(\frac{i_{k, t}}{i_{k, t-1}}-1\right)^{2}\right) i_{k, t}
$$

Price of capital

$$
\begin{aligned}
p_{i k, t}=p_{k, t}\left(1-\frac{\kappa_{k}}{2}\left(\frac{i_{k, t}}{i_{k, t-1}}-1\right)^{2}-\kappa_{k}\right. & \left.\left(\frac{i_{k, t}}{i_{k, t-1}}-1\right) \frac{i_{k, t}}{i_{k, t-1}}\right)+ \\
& +\beta_{P} \mathbb{E}_{t}\left\{\frac{u_{P, t+1}}{u_{P, t}} p_{k, t+1} \kappa_{k}\left(\frac{i_{k, t+1}}{i_{k, t}}-1\right)\left(\frac{i_{k, t+1}}{i_{k, t}}\right)^{2}\right\}
\end{aligned}
$$

Housing accumulation

$$
\chi_{t}=\left(1-\delta_{\chi}\right) \chi_{t-1}+\left(1-\frac{\kappa_{\chi}}{2}\left(\frac{i_{\chi, t}}{i_{\chi, t-1}}-1\right)^{2}\right) i_{\chi, t}
$$

Price of housing

$$
\begin{aligned}
p_{H, t}=p_{\chi, t}\left(1-\frac{\kappa_{\chi}}{2}\left(\frac{i_{\chi, t}}{i_{\chi, t-1}}-1\right)^{2}-\right. & \left.\kappa_{\chi}\left(\frac{i_{\chi, t}}{i_{\chi, t-1}}-1\right) \frac{i_{\chi, t}}{i_{\chi, t-1}}\right)+ \\
& +\beta_{P} \mathbb{E}_{t}\left\{\frac{u_{P, t+1}}{u_{P, t}} p_{\chi, t+1} \kappa_{\chi}\left(\frac{i_{\chi, t+1}}{i_{\chi, t}}-1\right)\left(\frac{i_{\chi, t+1}}{i_{\chi, t}}\right)^{2}\right\}
\end{aligned}
$$

\section{Final goods producers}

Aggregators

$$
\begin{gathered}
c_{t}=\left(\left(1-\eta_{c}\right)^{\frac{1}{\phi_{c}}} c_{F, t}^{\frac{\phi_{c}-1}{\phi_{c}}}+\eta_{c}^{\frac{1}{\phi_{c}}} c_{H, t}^{\frac{\phi_{c}-1}{\phi_{c}}}\right)^{\frac{\phi_{c}}{\phi_{c}-1}} \\
i_{k, t}=\left(\left(1-\eta_{k}\right)^{\frac{1}{\phi_{k}}} i_{k F, t}^{\frac{\phi_{k}-1}{\phi_{k}}}+\eta_{k}^{\frac{1}{\phi_{k}}} i_{k H, t}^{\frac{\phi_{k}-1}{\phi_{k}}}\right)^{\frac{\phi_{k}}{\phi_{k}-1}}
\end{gathered}
$$


Demand equations

$$
\begin{gathered}
c_{F, t}=\left(1-\eta_{c}\right) p_{F, t}^{-\phi_{c}} c_{t} \\
c_{H, t}=\eta_{c} p_{H, t}^{-\phi_{c}} c_{t} \\
i_{k F, t}=\left(1-\eta_{k}\right)\left(\frac{p_{F, t}}{p_{i k, t}}\right)^{-\phi_{k}} i_{k, t} \\
i_{k H, t}=\eta_{k}\left(\frac{p_{H, t}}{p_{i k, t}}\right)^{-\phi_{k}} i_{k, t}
\end{gathered}
$$

\section{Intermediate goods producers}

Marginal cost

$$
m c_{t}=\frac{1}{\alpha^{\alpha}(1-\alpha)^{1-\alpha}} \frac{1}{\varepsilon_{z, t}} r_{k, t}^{\alpha} w_{t}^{1-\alpha}
$$

Optimal factor proportions

$$
\frac{r_{k, t}}{w_{t}}=\frac{\alpha}{1-\alpha} \frac{n_{t}}{k_{t-1}}
$$

Optimal prices set by reoptimizing firms for domestic market and exports

$$
\begin{aligned}
& \tilde{p}_{H, t}=\mu \frac{\Omega_{H, t}}{\Upsilon_{H, t}} \\
& \tilde{p}_{H, t}^{*}=\mu \frac{\Omega_{H, t}^{*}}{\Upsilon_{H, t}^{*}}
\end{aligned}
$$

Auxiliary functions for optimal prices

$$
\begin{gathered}
\Omega_{H, t}=u_{P, t} m c_{t} p_{H, t}^{\frac{\mu}{\mu-1}} y_{H, t}+\beta_{P} \theta_{H} \mathbb{E}_{t}\left\{\left(\frac{\pi}{\pi_{t+1}}\right)^{\frac{\mu}{1-\mu}} \Omega_{H, t+1}\right\} \\
\Omega_{H, t}^{*}=u_{P, t} m c_{t}\left(p_{H, t}^{*}\right)^{\frac{\mu}{\mu-1}} y_{H, t}^{*}+\beta_{P} \theta_{H}^{*} \mathbb{E}_{t}\left\{\left(\frac{\pi^{*}}{\pi_{t+1}^{*}}\right)^{\frac{\mu}{1-\mu}} \Omega_{H, t+1}^{*}\right\} \\
\Upsilon_{H, t}=u_{P, t} p_{H, t}^{\frac{\mu}{\mu-1}} y_{H, t}+\beta_{P} \theta_{H} \mathbb{E}_{t}\left\{\left(\frac{\pi}{\pi_{t+1}}\right)^{\frac{1}{1-\mu}} \Upsilon_{H, t+1}\right\} \\
\Upsilon_{H, t}^{*}=u_{P, t} q_{t}\left(p_{H, t}^{*}\right)^{\frac{\mu}{\mu-1}} y_{H, t}^{*}+\beta_{P} \theta_{H}^{*} \mathbb{E}_{t}\left\{\left(\frac{\pi^{*}}{\pi_{t+1}^{*}}\right)^{\frac{1}{1-\mu}} \Upsilon_{H, t+1}^{*}\right\}
\end{gathered}
$$


Price indexes for goods produced domestically and for exports

$$
\begin{gathered}
p_{H, t}^{\frac{1}{1-\mu}}=\theta_{H}\left(p_{H, t-1} \frac{\pi}{\pi_{t}}\right) \frac{1}{1-\mu}+\left(1-\theta_{H}\right) \tilde{p}_{H, t}^{\frac{1}{1-\mu}} \\
\left(p_{H, t}^{*}\right)^{\frac{1}{1-\mu}}=\theta_{H}^{*}\left(p_{H, t-1}^{*} \frac{\pi^{*}}{\pi_{t}^{*}}\right)^{\frac{1}{1-\mu}}+\left(1-\theta_{H}^{*}\right)\left(\tilde{p}_{H, t}^{*}\right)^{\frac{1}{1-\mu}}
\end{gathered}
$$

\section{Importing firms}

Optimal prices set by reoptimizing importers

$$
\tilde{p}_{F, t}=\mu \frac{\Omega_{F, t}}{\Upsilon_{F, t}}
$$

Auxiliary functions for optimal prices

$$
\begin{gathered}
\Omega_{F, t}=u_{P, t} q_{t} p_{F, t}^{\frac{\mu}{\mu-1}} y_{F, t}+\beta_{P} \theta_{F} \mathbb{E}_{t}\left\{\left(\frac{\pi}{\pi_{t+1}}\right)^{\frac{\mu}{1-\mu}} \Omega_{F, t+1}\right\} \\
\Upsilon_{F, t}=u_{P, t} p_{F, t}^{\frac{\mu}{\mu-1}} y_{F, t}+\beta_{P} \theta_{F} \mathbb{E}_{t}\left\{\left(\frac{\pi}{\pi_{t+1}}\right)^{\frac{1}{1-\mu}} \Upsilon_{F, t+1}\right\}
\end{gathered}
$$

Price index for imports

$$
p_{F, t}^{\frac{1}{1-\mu}}=\theta_{F}\left(p_{F, t-1} \frac{\pi}{\pi_{t}}\right) \frac{1}{1-\mu}+\left(1-\theta_{F}\right) \tilde{p}_{F, t}^{\frac{1}{1-\mu}}
$$

\section{Banks}

Interest on loans

$$
\begin{gathered}
R_{H, t}=\mu_{L} R_{t} \\
R_{F, t}=\mu_{L} \rho_{t} R_{t}^{*}
\end{gathered}
$$

Uncovered interest rate parity

$$
\mathbb{E}_{t}\left\{u_{P, t+1}\left(\frac{R_{t}}{\pi_{t+1}}-\frac{q_{t+1}}{q_{t}} \frac{\rho_{t} R_{t}^{*}}{\pi_{t+1}^{*}}\right)\right\}=0
$$

Risk premium

$$
\rho_{t}=1+\varrho\left[\exp \left(\frac{d_{t}^{*} q_{t}}{y_{t}}-\frac{d^{*} q}{y}\right)-1\right]+\epsilon_{\rho, t}
$$




\section{Fiscal and monetary authority}

Taxes levied on impatient households

$$
\omega_{I} t_{I, t}=\tau_{I} p_{H, t} g_{t}
$$

Taylor rule

$$
\frac{R_{t}}{R}=\left(\frac{R_{t-1}}{R}\right)^{\gamma_{R}}\left[\left(\frac{\pi_{t}}{\pi}\right)^{\gamma_{\pi}}\left(\frac{y_{t}}{y}\right)^{\gamma_{y}}\right]^{1-\gamma_{R}} \varepsilon_{R, t}
$$

\section{Market clearing}

Production for domestic market

$$
y_{H, t}=c_{H, t}+i_{k H, t}+i_{\chi, t}+g_{t}
$$

Imports

$$
y_{F, t}=c_{F, t}+i_{F k, t}
$$

Export demand

$$
y_{H, t}^{*}=\eta^{*}\left(p_{H, t}^{*}\right)^{-\phi_{y}^{*}} y_{t}^{*}
$$

Aggregate output

$$
y_{H, t} \Delta_{H, t}+y_{H, t}^{*} \Delta_{H, t}^{*}=\varepsilon_{z, t} k_{t-1}^{\alpha} n_{t}^{1-\alpha}
$$

GDP definition

$$
y_{t}=y_{H, t} \Delta_{H, t}+y_{H, t}^{*} \Delta_{H, t}^{*}
$$

Foreign debt accumulation

$$
d_{t}^{*}=\Delta_{F, t} y_{F, t}-p_{H, t}^{*} y_{H, t}^{*}+\varrho_{t-1} R_{t-1}^{*} \frac{d_{t-1}^{*}}{\pi_{t}^{*}}
$$

Price dispersion indexes

$$
\begin{aligned}
& \Delta_{H, t}=\theta_{H}\left(\frac{p_{H, t}}{p_{H, t-1}}\right)^{\frac{\mu}{\mu-1}} \Delta_{H, t-1}\left(\frac{\pi}{\pi_{t}}\right)^{\frac{\mu}{1-\mu}}+\left(1-\theta_{H}\right)\left(\frac{\tilde{p}_{H, t}}{p_{H, t}}\right)^{\frac{\mu}{1-\mu}} \\
& \Delta_{H, t}^{*}=\theta_{H}^{*}\left(\frac{p_{H, t}^{*}}{p_{H, t-1}^{*}}\right)^{\frac{\mu}{\mu-1}} \Delta_{H, t-1}^{*}\left(\frac{\pi^{*}}{\pi_{t}^{*}}\right)^{\frac{\mu}{1-\mu}}+\left(1-\theta_{H}^{*}\right)\left(\frac{\tilde{p}_{H, t}^{*}}{p_{H, t}^{*}}\right)^{\frac{\mu}{1-\mu}}
\end{aligned}
$$




$$
\Delta_{F, t}=\theta_{F}\left(\frac{p_{F, t}}{p_{F, t-1}}\right)^{\frac{\mu}{\mu-1}} \Delta_{F, t-1}\left(\frac{\pi}{\pi_{t}}\right)^{\frac{\mu}{1-\mu}}+\left(1-\theta_{F}\right)\left(\frac{\tilde{p}_{F, t}}{p_{F, t}}\right)^{\frac{\mu}{1-\mu}}
$$

Housing market

$$
\chi_{t}=\omega_{I} \chi_{I, t}+\left(1-\omega_{I}\right) \chi_{P, t}
$$

Wage dispersion indexes (for $i=\{I, P\}$ )

$$
\Delta_{w, i, t}=\theta_{w}\left(\frac{w_{i, t}}{w_{i, t-1}}\right)^{\frac{\mu_{w}}{\mu_{w}-1}\left(1+\sigma_{n}\right)} \Delta_{w, i, t-1}\left(\frac{\pi}{\pi_{t}}\right)^{\frac{\mu_{w}}{1-\mu_{w}}\left(1+\sigma_{n}\right)}+\left(1-\theta_{w}\right)\left(\frac{\tilde{w}_{i, t}}{w_{i, t}}\right)^{\frac{\mu_{w}}{1-\mu_{w}}\left(1+\sigma_{n}\right)}
$$

\section{Exogenous shocks}

The following variables are assumed to be driven by exogenous stochastic processes: productivity $\varepsilon_{z, t}$, risk premium $\varepsilon_{\rho, t}$, share of DCLs $\eta_{L, t}$, government spending $g_{t}$, monetary policy $\varepsilon_{R, t}$, macroprudential policy $m_{t}$, foreign output $y_{t}^{*}$, foreign inflation $\pi_{t}^{*}$ and foreign interest rate $R_{t}^{*}$. 